\title{
Study of the Factors Influencing Mortality from the Cerebral Stroke in Patients of Different Ages
}

\author{
Vazgen Martirosyan ${ }^{1}$ and Julia Krupskaya ${ }^{1 *}$ \\ ${ }^{1}$ Department of Nervous Diseases and Neurosurgery, Rostov State Medical University, \\ Rostov-on-Don 344000, Russia.
}

Authors' contributions

This work was carried out in collaboration between both authors. Both authors contributed to the interpretation of the data and were responsible for reviewing the manuscript. Both authors have read and approved the final manuscript

Research Article

Received $23^{\text {rd }}$ March 2013

Accepted $2^{\text {nd }}$ May 2013

Published 10 ${ }^{\text {th }}$ May 2013

\section{ABSTRACT}

Aims: To detect significant relationships between risk factors of cerebral stroke and the age of patients. Identify a number of exogenous factors among the geoheliomagnetic and meteorological ones which have a significant impact on the increase in the fatal outcome probability.

Study Design: Main research field: cerebral strokes.

Place and Duration of Study: The research is based on the results of retrospective analysis of the autopsy of people who died of cerebral stroke according to the data of the N.A. Semashko Municipal Hospital No 1 (Central Municipal Hospital) of Rostov-on-Don, Russia during the years of high (2000-2002) and low (2008-2010) solar activity.

Methodology: The study involves 1135 patients who died of cerebral stroke. 5 observation groups were formed depending on the age: 1 group: $34(3 \%)-$ less than 45 years old; 2 group: 200 (17.6\%) - between 45-59 years old; 3 group: 540 (47.6\%) between 60-74 years old; 4 group: $356(31.4 \%)$ - between $75-89$ years old; 5 group: 5 $(0.4 \%)-90$ and more years old. Nosological signs of disease and endogenous risk factors were recorded for each observation. To evaluate the complex impact of the environmental factors on the death rate of the vascular accidents, 44 exogenous risk factors were analyzed.

Results: With the help of multivariate logistic regression method, after the construction 
of a mathematical model, nine endogenous and 8 exogenous factors, from amount participating in the analysis, which can be factors of immediate death risk for the patients belonging to various age groups, were detected. The coincidence of fact and calculations according to the gradations of the classification variable containing the meaning of number of age group, is ensured in $68.2 \%$ of cases (Concordant),coefficient of association Somers'D: .371. Model quality was evaluated according to the modeling sample.

It is statistically proved, that death occurred with the patients of young and middle age because of diseases associated with hypertension, atherosclerosis of the 2-3 stage, alcohol. Characteristic CS type - hemorrhagic, especially hematoma class with blood breakthrough into the brain ventricles. Severe course of disease with frequent deaths in the 1st day are typical. In case of established combination of the pathogenic effect is mostly associated with high solar and geomagnetic activity.

Among the patients of the elderly and the senile age appeared patients with secondary arterial hypertension, atherosclerosis of the 3-4 stage, heart diseases in the form of ciliary arrhythmia and coronary heart disease. Characteristic CS type - ischemic, especially non-atherothrombotic class. Death during the 1st day was statistically less likely. The maximum meteotropic reactions occur with contrasting weather patterns change, quick change of air masses with different thermal properties.

Conclusion: Data about the discovered specific risk factors for the patients of different ages would allow choosing a more efficient individual approach to each patient aimed at improving the effectiveness of treatment and reducing the frequency of fatal outcomes.

Keywords: Cerebral stroke; logistic regression; prognostics; solar activity.

\section{DEFINITIONS, ACRONYMS, ABBREVIATIONS}

RR: Rostov Region; CMH: N.A. Semashko Central Municipal Hospital No 1; CVA: cerebrovascular accident; CS: cerebral stroke; ATB: atherothrombotic subclass of the ischemic stroke; non-ATB: non-atherothrombotic subclass of the ischemic stroke; RF: endogenous risk factors of stroke; EGF: nous risk factors of stroke; SA: Solar activity; A: diurnal range; $\Delta$ : day-to-day change; $t^{0}$ : average daily temperature; $p$ : average daily pressure; $h$ : average daily humidity; v: average daily wind force; $n$ : average daily cloud amount; l: meteorological pathogenicity index.

\section{INTRODUCTION}

The main cause of death in the Russian Federation, as well as in the rest of the world, is connected with cardiovascular diseases. The stroke is getting "younger" and also more widespread among the people of retirement age. The incidence and mortality from the stroke among the working-age population has grown over the past 10 years by more than $30 \%$. Only about $15-20 \%$ of the patients return to their previous professional life after stroke $[1,2,3]$.

Incidence of stroke in 2010 in the Rostov Region equaled 345.0 cases per 100 thousand people. The share of cerebrovascular disease in the disablement structure in 2010 made up $40 \%$. In order to reduce the incidence rate, disability and mortality from cerebrovascular diseases the Ministry of Health of the RR designed a long-term regional target program «Development of Healthcare in the RR in 2010-2013.» Among the other expected results of 
the Program there will be the stabilization of the incidence of stroke and myocardial infarction between 2011 and 2013 at the level decreased by $12 \%$ as compared to 2010 , as well as reduction of the death rate from cerebrovascular diseases down to 205.0 cases per 100 thousand people by 2013.

The importance of the problem of stroke among the patients of young age lies in the following: the etiology of stroke of a large part of young patients is different from the etiology of stroke of the patients of older age groups and often remains unclear. It has essential value for the qualified prevention of recurrent stroke, as the examination procedure of the patients with stroke of the young age is not fully developed yet; medical and social significance of the study of stroke among the people who are in their prime, are of childbearing age, often at the top of their creative and professional life. The incidence of stoke in the young age varies according to the data of different scientists between 2.5 and $10 \%$ off all the strokes of the study population $[4,5,6]$. It is necessary to take measures aimed at realization of the preventive approach to fighting with the incidence and mortality from the stroke among the young patients. Control of the proven risk factors will ensure the reduction of the disease probability throughout life.

This study provides a comprehensive assessment of the factors that determine the outcome of stroke in patients of different ages. Special attention is paid to finding the specific factors that lead to vascular accidents characteristic of young patients.

The initial hypothesis lies in the assumption that there are some statistically significant links between the set of indications reflecting characteristics of acute cerebrovascular accidents (CVA), exogenous factors that accompany the onset of stroke (EGF) and the age of the patients who had cerebral stroke (CS).

\section{MATERIALS AND METHODS}

The research is based on the results of retrospective analysis of the autopsy of people who died of CS (1135 cases in total) during the years of high (2000-2002) and low (2008-2010) solar activity according to the data of the N.A. Semashko Municipal Hospital No 1 (Central Municipal Hospital) of Rostov-on-Don, Russia, where the people with MI were normally hospitalized. Based on the recommendations of the WHO five groups of observations were formed:

First observation group (group of the young) - 34 (3\%) patients - formed from patients whose age was less than 45 years;

Second observation group (group of the middle-aged) - 200 (17.6\%) patients - formed from patients whose age was in the range $45-59$ years;

Third observation group (group of the elderly) - 540 (47.6\%) patients - formed from patients whose age was in the range 60-74 years;

Fourth observation group (senile group) - 356 (31.4\%) patients - formed from patients whose age was in the range 75-89 years;

Fifth observation group (group of long-livers) - $5(0.4 \%)$ patients - formed from patients whose age was 90 years old and more; 
All the cases of stroke were subdivided according to: sex (males, females), type (ischemic and hemorrhagic strokes), site (right, left hemisphere or brainstem). Ischemic strokes are subdivided in their turn into atherothrombotic (ATB) and non-atherothrombotic (non-ATB). Hemorrhagic strokes are classified into subarachnoidal, hematomas and hematomas with the breakthrough of blood into the ventricles of the brain. For every case the date of the CS onset and the date of death were recorded. Individual survival terms were counted; cases of mortality in the 1st day were identified. The character of CS development was taken into account (suddenly, gradually). The following RF of stroke was accounted: hypertension, cerebral atherosclerosis, diabetes, heart disease, CVA history, kidney disease, alcohol abuse. The complex influence of the environmental factors on mortality from CVA was evaluated in the 5 observation groups during the periods indicated with the SA. 44 indications from the range of EGF were analyzed:

Subgroup SA - 22 indications in total. Basic planetary heliophysical indices characterizing solar activity, including: "SA Index»; «ISN», "ISNn», "ISNs», "Sunspot Area», "SFU», «XRay Bkgd Flux», «Flares X-Ray (class C, M. X)», «Proton Fluence (>1 MeV; >10 MeV; >100 $\mathrm{MeV})$ ), «Electron Fluence (>0.6 MeV; >2 MeV)», «Bx», «By», «Bz», «ION Density», «Bulk Flow speed», "Temp ION». Data about heliophysical parameters were obtained from the catalogues Space Environment Center (Link: http://sec.noaa.gov) and National Space Science Data Center (Link: http://nssdc.gsfc.nasa.gov).

Subgroup GM - 6 indications in total. Classic planetary heliophysical indices, including: «Kp», «Ap», «Aa», «DST», «Cp», «C9». The range of heliophysical indices was obtained from the catalogues SPIDR (Space Physics Interactive Data Resource), located at the website Link: http://spidr.ngdc.noaa.gov/spidr.

Subgroup MD - 15 indications in total. Daily means of the 5 basic meteorological characteristics in Rostov-on -Don in the periods 2000-2002 and 2008-2010, including: air temperature $\left(t^{0}\right)$, relative humidity $(h)$, atmospheric pressure $(p)$, wind force $(v)$ and cloudiness $(n)$. Their diurnal ranges $(A)$ and day-to-day change $(\Delta)$ was also calculated. Records of weather in Rostov-on-Don in 2000-2002 and 2008-2010 were used (weather station «Rostov-on-Don»). Atmospheric pressure at the height of the weather station $75 \mathrm{~m}$ above sea level, measuring frequency - every 3 hours. Records catalogues are located at the website: Link: http://rostovmeteo.ru/.

Subgroup IP - 1 indication. The total daily values of meteorological pathogenicity index were calculated (I) [7].

Graphic demonstration of the SA in sunspot relative numbers (ISN) (Fig.1) and the values of the radio emission flux on the wave $10.7 \mathrm{~cm}$ (SFU) (Fig. 2) were obtained for the period 2000-2010. 


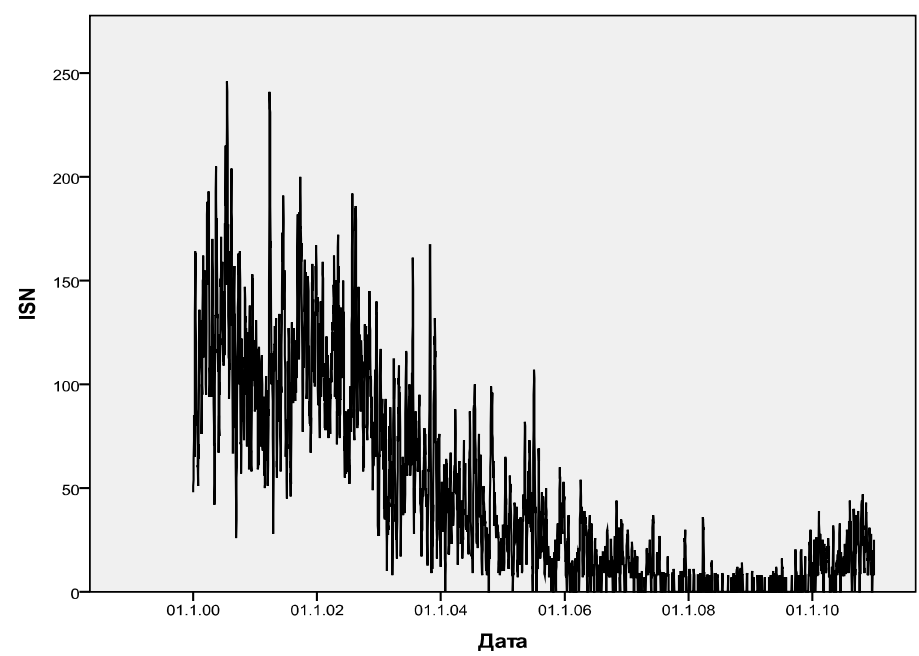

Fig. 1. Graphic demonstration of the SA in sunspot relative numbers (ISN) for the period 2000-2010

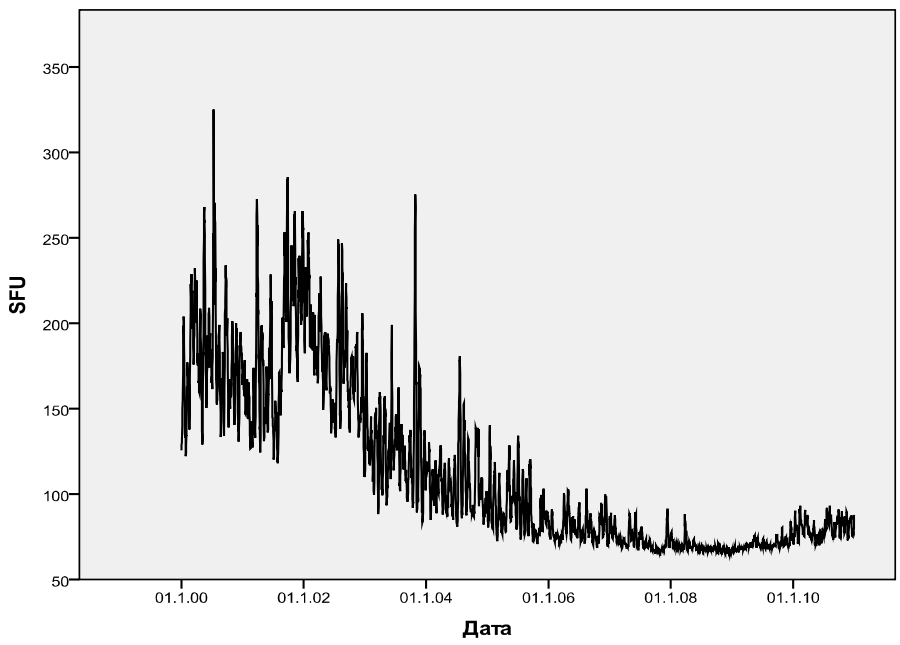

Fig. 2. Graphic demonstration of the SA in the values of the radio emission flux on the wave $10.7 \mathrm{~cm}$ (SFU) for the period 2000-2010

To confirm or refute the initial hypothesis it was decided to limit the study to the periods 2000-2002- years of high SA and 2008-2010- years of low SA.

Statistical analysis was carried out at the BIOSTATISTICS Center, under the guidance of VP Leonov, Computer Science Department Associate Professor of Tomsk State University, $\mathrm{Ph} . \mathrm{D}$. Statistical analysis procedures were conducted with the help of statistic packages SAS 9.2, STATISTICA 10 and SPSS-20. During testing the null hypotheses the critical value of statistical significance was taken as: $P=.05$. If the achieved level of the statistical criterion significance of this value was exceeded, the null hypothesis was accepted. 
The check of normalcy of distribution of quantitative characters in separate comparison groups was performed using the criterion Kolmogorov-Smirnov. For comparison of the central group parameters parametric and non-parametric methods were used: variance analysis including the criterion Kruskal-Wallis, for all the quantitative attributes in the compared groups arithmetic and average squared (standard) errors of mean and coefficient of variation were evaluated. Descriptive statistics are given in the text as $M \pm m$, where $M-$ mean, a $\mathrm{m}$ - error of mean.

To analyze the relationship between one qualitative character, acting as a dependent, the resulting index (in this case it was the parameter "AGE» with gradation "young», «middle», «elderly», "senile» and "long-liver»), and a subset of the qualitative and quantitative characteristics, logistic regression model with an incremental algorithm of the inclusion and exclusion of predictors was used. Results of estimating logistic regression equations are a presented as a set of regression coefficients, significance levels reached for each coefficient, and the assessment are index of concordance (Concordant) of the actual belonging of a patient to a particular age group and theoretical origin, derived from the equation of the logit regression. A total of about twenty logit-regression equations were obtained, out of which the equations that have the highest values of this index were selected. The selected predictors were ranked by the connection degree with the dependent variable by sorting the predictors according to standardized regression coefficients module $[8,9]$. Model quality was evaluated according to the modeling sample.

The relationship between pairs of discrete qualitative characteristics was examined by analyzing paired contingency tables. In addition to ratings Pearson Chi-square and the reached level of statistical significance of this criterion, the ratings of the connection intensity of the analyzed characteristics, such as Cramer's V, were also calculated [10]. If there was a statistically significant relationship between a pair of qualitative characteristics an in-depth analysis of the distribution of frequencies in the boxes of contingency table was carried out, which allowed to determine the structure of the revealed the relationship at the level of combinations of the individual gradations of both characteristics.

\section{RESULTS AND DISCUSSION}

Lethality" is one of the most important indicators of hospital activity. Based on the reports of the "medical-diagnostic work," of the N.A. Semashko Municipal Hospital No 1 (CMH) of Rostov-on-Don, during the whole time the figure remained at a high level with an increase over the analyzed years. Thus, in 2010 mortality rate was $16.85 \%$, and in 2009 and 2008 $15.88 \%$ and $14.95 \%$, respectively. First of all, this was due to the increased share of patients admitted to hospital by "emergency", with a variety of urgent neurological conditions (primarily CVA) in serious and critical state, as well as due to the change of the age of the patients with an increase in the proportion of elderly patients and patients of senile age. It was also mentioned that the increase of mortality rate in 2010 was adversely affected by severe weather conditions in the summer (heat) reducing the responsiveness of the human body, especially in the elderly and old age, and negatively affecting the microclimate inside the hospital.

Among thenosological causes of the lethal outcomes blood circulation diseases retained the leading position (ICD code 100-99, including 160-69): $94.2 \%$ of the total number of deaths in 2010 , and $87.2 \%$ in 2009. The major share of this class held cardioembolic strokes: in 2010 $75.2 \%$, in $2009-67.8 \%$, haemorrhages of the brain accounted for $18.2 \%$ (2010) and $24.6 \%$ (2009), subarachnoid hemorrhage - 1.7\% (2010) and $1.7 \%$ (2009). 
Taking into account that the most reliable data for medical statistics are the results of postmortem studies, autopsy reports of deaths from CS during the study period were analyzed. At the initial stage of research was conducted a retrospective analysis of the distribution of death cases based on the age group of the patient.

The distribution of the received frequency from year to year within the period of the study is presented in Table 1.

Table 1. Mortality dynamics from CVA in the neurology unit of CMH $f$ Rostov-on-Don from year to year

\begin{tabular}{lllllllll}
\hline Group & & \multicolumn{9}{c}{ Year } & Total \\
\cline { 3 - 7 } & & $\mathbf{2 0 0 0}$ & $\mathbf{2 0 0 1}$ & $\mathbf{2 0 0 2}$ & $\mathbf{2 0 0 8}$ & $\mathbf{2 0 0 9}$ & $\mathbf{2 0 1 0}$ & \\
\hline 1 («young») & frequency & 4 & 4 & 7 & 7 & 5 & 7 & 34 \\
& $\%$ & $5.3 \%$ & $4.1 \%$ & $6.2 \%$ & $3.0 \%$ & $1.8 \%$ & $2.1 \%$ & $3.0 \%$ \\
2 («middle») & frequency & 16 & 19 & 28 & 54 & 42 & 41 & 200 \\
& $\%$ & $21.1 \%$ & $19.4 \%$ & $24.8 \%$ & $22.9 \%$ & $14.9 \%$ & $12.4 \%$ & $17.6 \%$ \\
3 («elderly») & frequency & 45 & 55 & 62 & 104 & 135 & 139 & 540 \\
& $\%$ & $59.2 \%$ & $56.1 \%$ & $54.9 \%$ & $44.1 \%$ & $47.9 \%$ & $42.1 \%$ & $47.6 \%$ \\
4 («senile») & frequency & 10 & 20 & 16 & 70 & 98 & 142 & 356 \\
& $\%$ & $13.2 \%$ & $20.4 \%$ & $14.2 \%$ & $29.7 \%$ & $34.8 \%$ & $43.0 \%$ & $31.4 \%$ \\
5 («long-livers») & frequency & 1 & 0 & 0 & 1 & 2 & 1 & 5 \\
& $\%$ & $1.3 \%$ & $.0 \%$ & $.0 \%$ & $.4 \%$ & $.7 \%$ & $.3 \%$ & $.4 \%$ \\
Total & frequency & 76 & 98 & 113 & 236 & 282 & 330 & 1135 \\
& $\%$ & $100 \%$ & $100 \%$ & $100 \%$ & $100 \%$ & $100 \%$ & $100 \%$ & $100 \%$ \\
\hline
\end{tabular}

The dependence of frequency of deaths from high and low SA deserves consideration. At first glance the influence of the Sun does not depend on the intensity of SA for the patients who died at a young age. Death rate among middle-aged patients increased significantly during low SA. Similar situation is observed among the elderly, and especially in the senile group. (Table 2).

Table 2. Mortality dynamics from CVA in the neurology unit of CMH of Rostov-on-Don according to SA periods

\begin{tabular}{|c|c|c|c|c|c|c|c|}
\hline \multirow[t]{2}{*}{$\overline{\text { SA }}$} & & \multicolumn{5}{|l|}{ Group } & \multirow[t]{2}{*}{ Total } \\
\hline & & "young» & «middle» & "elderly» & "senile» & «long-livers» & \\
\hline \multirow{2}{*}{$\overline{\text { of high SA }}$} & frequency & 19 & 137 & 378 & 310 & 4 & 848 \\
\hline & & $2.2 \%$ & $16.2 \%$ & $44.6 \%$ & $36.6 \%$ & $.5 \%$ & $100 \%$ \\
\hline \multirow[t]{2}{*}{ of low SA } & frequency & 15 & 63 & 162 & 46 & 1 & 287 \\
\hline & & $5.2 \%$ & $22.0 \%$ & $56.4 \%$ & $16.0 \%$ & $.3 \%$ & $100 \%$ \\
\hline \multirow[t]{2}{*}{ Total } & frequency & 34 & 200 & 540 & 356 & 5 & 1135 \\
\hline & $\%$ & $3.0 \%$ & $17.6 \%$ & $47.6 \%$ & $31.4 \%$ & $.4 \%$ & $100 \%$ \\
\hline
\end{tabular}

Over the entire study period was observed 758 (66.8\%) ischemic strokes, $277(33.2 \%)$ intracerebral hemorrhages of the total number of CS (1135 people), including: ATB - 74 (6.5\%); non-ATB - 684 (60.3\%); subarachnoid- 21 (1.9\%), hematomas - $173(15.2 \%)$, and hematomas with a breakthrough of blood into the brain ventricles $-183(16.1 \%)$. The distribution of frequency of the CS subtypes according to the age group is presented in Table 3. 
Table 3. Frequency distribution of the CS subtypes in the scope of the research with consideration of the patient's age group

\begin{tabular}{|c|c|c|c|c|c|c|c|}
\hline \multirow[t]{2}{*}{ Group } & & \multicolumn{5}{|c|}{ Type of cerebral stroke } & \multirow[t]{2}{*}{ Total } \\
\hline & & $\begin{array}{l}\text { Subarach- } \\
\text { noidal }\end{array}$ & hematomas & $\begin{array}{l}\text { hematomas } \\
\text { with the } \\
\text { breakthrough }\end{array}$ & ATB & non-ATB & \\
\hline young & $\begin{array}{l}\text { frequency } \\
\%\end{array}$ & $\begin{array}{l}2 \\
9.5 \%\end{array}$ & $\begin{array}{l}9 \\
5.2 \%\end{array}$ & $\begin{array}{l}11 \\
6.0 \%\end{array}$ & $\begin{array}{l}3 \\
4.1 \%\end{array}$ & $\begin{array}{l}9 \\
1.3 \%\end{array}$ & $\begin{array}{l}34 \\
3.0 \%\end{array}$ \\
\hline middle & $\begin{array}{l}\text { frequency } \\
\%\end{array}$ & $\begin{array}{l}8 \\
38.1 \%\end{array}$ & $\begin{array}{l}42 \\
24.3 \%\end{array}$ & $\begin{array}{l}53 \\
29.0 \%\end{array}$ & & $\begin{array}{l}83 \\
12.1 \%\end{array}$ & $\begin{array}{l}200 \\
17.6 \%\end{array}$ \\
\hline elderly & $\begin{array}{l}\text { frequency } \\
\%\end{array}$ & $\begin{array}{l}8 \\
38.1 \%\end{array}$ & $\begin{array}{l}70 \\
40.5 \%\end{array}$ & $\begin{array}{l}95 \\
51.9 \%\end{array}$ & $\begin{array}{l}40 \\
54.1 \%\end{array}$ & $\begin{array}{l}327 \\
47.8 \%\end{array}$ & $\begin{array}{l}540 \\
47.6 \%\end{array}$ \\
\hline senile & $\begin{array}{l}\text { frequency } \\
\%\end{array}$ & $\begin{array}{l}3 \\
14.3 \%\end{array}$ & $\begin{array}{l}52 \\
30.1 \%\end{array}$ & $\begin{array}{l}23 \\
12.6 \%\end{array}$ & $\begin{array}{l}17 \\
23.0 \%\end{array}$ & $\begin{array}{l}261 \\
38.2 \%\end{array}$ & $\begin{array}{l}356 \\
31.4 \%\end{array}$ \\
\hline $\begin{array}{l}\text { long- } \\
\text { livers }\end{array}$ & frequency & $\begin{array}{l}0 \\
0 \%\end{array}$ & $\begin{array}{l}0 \\
0 \%\end{array}$ & $\begin{array}{l}1 \\
5 \%\end{array}$ & $\begin{array}{l}0 \\
0 \%\end{array}$ & $\begin{array}{l}4 \\
6 \%\end{array}$ & 5 \\
\hline Total & $\begin{array}{l}\text { frequency } \\
\%\end{array}$ & $\begin{array}{l}21 \\
100 \%\end{array}$ & $\begin{array}{l}173 \\
100 \%\end{array}$ & $\begin{array}{l}183 \\
100 \%\end{array}$ & $\begin{array}{l}74 \\
100 \%\end{array}$ & $\begin{array}{l}684 \\
100 \%\end{array}$ & $\begin{array}{l}1135 \\
100 \%\end{array}$ \\
\hline
\end{tabular}

According to the site: right-sided CS - $436(38.4 \%)$, left-sided $-527(46.4 \%)$ and brainstem $172(15.2 \%)$. In the population women occurred more often than men, $606(53.4 \%)$ and 529 $(46.6 \%)$, respectively. Death in the 1st day after the CS onset occurred with $120(10.6 \%)$ patients.

Among the stroke RF hypertension was present in $87 \%$ of patients. In $87.7 \%$ of cases atherosclerosis of 3-4 degree was observed. Heart disease accounted for $89.2 \%$. For $72.8 \%$ of patients CS was the first, and for $27.2 \%$ - recurrent. Kidney disease and diabetes were observed in $26.5 \%$ and $19.3 \%$ of those who died of CS, respectively. $7.8 \%$ suffered from alcoholism.

Of specific interest are the clinical features of CS in patients from the fifth observation group (group of long-livers: => 90 years). This population included 5 people, 1 male and 4 females. Four people suffered ischemic type of CS, primary localization - left-sided (80\%). In 100\% a history of heart disease, secondary hypertension and atherosclerosis of 3-4 stage was observed. The average survival period after the onset of CS was 8.6 days.

The relationship between EGF complex (subgroups SA, GM, MD, and IP), participating in the analysis, RF, endogenous factors, reflecting the characteristics of CVA, on the one hand, and the age group of the patients who suffered CS, on the other, was examined. To accomplish the set task, a new classification variable GRUP_MI was generated, containing the number of the age group to which each particular observation applies. The purpose of using logistic regression method is to assess the relationship of the output dependent discrete factor (in this case GRUP_MI) with a set of qualitative and quantitative predictors.

As a result of the conducted research during construction of the mathematical model nine endogenous factors reflecting the characteristics of CVA and 8 EGF were found, this indicates that the difference between the structure of the 5 formed age groups is divided by fairly large sector indicators. 
The coincidence of fact and calculations by gradations of the classification variable GRUP_MI of the traits group 1 («young»), group 2 («middle»), group 3 («elderly»), group 4 («senile») and Group 5 («long-livers») in array of research was provided in $68.2 \%$ cases (Concordant), the coupling coefficient D-Sommer (Somers'D) was 0.371 . The obtained data is presented in Table 4.

Table 4. Evaluation of the logistic regression parameters

\begin{tabular}{|c|c|c|c|c|c|}
\hline № & Predictor & $\begin{array}{l}\text { Coefficient } \\
\text { (B) }\end{array}$ & $\begin{array}{l}\text { Standard } \\
\text { error }\end{array}$ & $\begin{array}{l}\text { Wald } \\
\text { Chi-Square }\end{array}$ & $\begin{array}{l}\text { Pr }> \\
\text { ChiSq }\end{array}$ \\
\hline 1 & 2 & 3 & 4 & 5 & 6 \\
\hline & Intercept «middle» & -14.707 & 6.498 & 5.121 & .023 \\
\hline & Intercept «elderly» & -12.212 & 6.496 & 3.533 & .040 \\
\hline & Intercept «senile» & -9.333 & 6.495 & 2.064 & .050 \\
\hline & Intercept «long-livers» & -9.183 & 6.495 & 1.998 & .057 \\
\hline 1 & Sex & -0.419 & 0.087 & 22.842 & .001 \\
\hline 2 & Type of cerebral stroke & -0.155 & 0.051 & 9.034 & .003 \\
\hline 3 & Death in the $1^{\text {st }}$ day & 0.373 & 0.096 & 15.093 & .001 \\
\hline 4 & Hypertension & 0.562 & 0.102 & 30.389 & .001 \\
\hline 5 & Alcoholism & 0.995 & 0.161 & 37.837 & .001 \\
\hline 6 & Atherosclerosis & -0.244 & 0.042 & 32.796 & .001 \\
\hline 7 & Coronary heart disease & -0.240 & 0.137 & 3.060 & .050 \\
\hline 8 & Ciliary arrhythmia & -0.386 & 0.100 & 14.704 & .001 \\
\hline 9 & Secondary arterial hypertension & -0.309 & 0.107 & 8.365 & .004 \\
\hline 10 & SA Index & 0.948 & 0.284 & 11.085 & .001 \\
\hline 11 & SFU & 0.006 & 0.002 & 5.958 & .015 \\
\hline 12 & Кр & 0.048 & 0.025 & 3.545 & .040 \\
\hline 13 & $\begin{array}{l}\text { Meteorological pathogenicity index } \\
\text { (I) }\end{array}$ & -0.119 & 0.036 & 10.622 & .001 \\
\hline 14 & Daily temperature amplitude $\left(\mathrm{A} \mathrm{t}^{0}\right)$ & 0.009 & 0.004 & 4.877 & .027 \\
\hline 15 & Day to day changes in temp. $\left(\Delta \mathrm{t}^{0^{\prime}}\right)$ & -0.058 & 0.024 & 5.536 & .019 \\
\hline 16 & Average daily wind speed (v) & -0.019 & 0.008 & 5.249 & .022 \\
\hline 17 & $\begin{array}{l}\text { Day to day changes in cloudiness } \\
(\Delta \mathrm{n})\end{array}$ & -0.005 & 0.002 & 3.255 & .041 \\
\hline
\end{tabular}

In this case the value of the first category («young») of the classification variable GRUP_MI is appointed contrast variable, and the value of its logistic coefficient (Intercept) is taken for 0 , and does not appear in the table of parameter estimation.

Each of the regression coefficients $\mathrm{Bi}$ (col. 3 Table 4.) describes the contribution of the corresponding predictor. Positive regression coefficient indicates that this factor increases the probability of the fact that the patient belongs to the estimated age group (in this case, "young»), while negative coefficient indicates that this factor reduces the probability. High statistics coefficient Wald Chi-Square (col. 5 Table 4.) means that this factor significantly affects the total probability, while the near-zero coefficient means that this factor has little effect on the probability of result.

Based on data from Table 4 a mathematical model for calculating the probability of belonging of each patient who suffered from CVA to a particular age group was created. 
Logistic regression equation which describes the probability of the outcome has the following form (1):

$$
P=\frac{e^{\text {beta }}}{1+e^{\text {beta }}} \quad \text { beta }=\mathrm{B}_{0}+\mathrm{B}_{1}{ }^{*} \mathrm{X}_{1}+\mathrm{B}_{2}{ }^{*} \mathrm{X}_{2}+\ldots+\mathrm{B}_{17}{ }^{*} \mathrm{X}_{17}
$$

Here:

$P$ - the probability of belonging of the patient who suffered from CS to the estimated age group;

$B_{0}$ - absolute term, intersection (Intercept);

$B_{1}, \ldots, B_{17}$ - regression coefficients for the influencing factors $X$;

$X_{1}, \ldots, X_{17}-$ values of the influencing variables, where values can be both quantitative and discrete.

To work with a model coding Table 5 was drawn, which provides a set of 17 selected features, coefficient and codes (values $\mathrm{Xi}$ ) of components for each feature.

Table 5. Coding table of the logistic regression model

\begin{tabular}{|c|c|c|c|c|c|c|c|}
\hline № & $\begin{array}{l}\text { Coefficient } \\
\left(B_{i}\right)\end{array}$ & Predictor & $\begin{array}{l}\text { Code } \\
\left(X_{i}\right)\end{array}$ & № & $\begin{array}{l}\text { Coefficient } \\
\left(B_{i}\right)\end{array}$ & Predictor & $\begin{array}{l}\text { Code } \\
\left(X_{i}\right)\end{array}$ \\
\hline \multicolumn{8}{|c|}{ Discrete traits } \\
\hline \multirow[t]{3}{*}{1} & Sex & & & 2 & \multicolumn{3}{|c|}{ Type of cerebral stroke } \\
\hline & -0.419 & Male & 1 & & -0.155 & Hemorrhagic & 0 \\
\hline & & Female & 2 & & & Ischemic & 1 \\
\hline \multirow[t]{2}{*}{3} & \multicolumn{3}{|c|}{ Death in the $1^{\text {st }}$ day } & & \multicolumn{3}{|c|}{ Hypertension } \\
\hline & 0.373 & $\begin{array}{l}\text { Survived } \\
\text { Died }\end{array}$ & $\begin{array}{l}0 \\
1\end{array}$ & 4 & 0.562 & $\begin{array}{l}\text { Healthy } \\
\text { ill }\end{array}$ & $\begin{array}{l}0 \\
1\end{array}$ \\
\hline \multirow[t]{2}{*}{5} & \multicolumn{3}{|l|}{ Alcoholism } & & \multicolumn{3}{|c|}{ Atherosclerosis } \\
\hline & 0.995 & $\begin{array}{l}\text { Healthy } \\
\text { ill }\end{array}$ & $\begin{array}{l}0 \\
1\end{array}$ & 6 & -0.244 & $\begin{array}{l}0-2 \text { stage } \\
3-4 \text { stage }\end{array}$ & $\begin{array}{l}0 \\
1\end{array}$ \\
\hline \multirow[t]{2}{*}{7} & \multicolumn{3}{|c|}{ Coronary heart disease } & & \multicolumn{3}{|c|}{ Ciliary arrhythmia } \\
\hline & -0.240 & $\begin{array}{l}\text { Healthy } \\
\text { ill }\end{array}$ & $\begin{array}{l}0 \\
1\end{array}$ & 8 & -0.386 & $\begin{array}{l}\text { Healthy } \\
\text { ill }\end{array}$ & $\begin{array}{l}0 \\
1\end{array}$ \\
\hline \multirow[t]{3}{*}{9} & \multicolumn{3}{|c|}{ Secondary arterial hypertension } & \multicolumn{3}{|c|}{ SA Index } & \\
\hline & -0.309 & Healthy & 0 & 10 & 0.948 & of high SA & 0 \\
\hline & & ill & 1 & & & of low SA & 1 \\
\hline \multicolumn{8}{|c|}{ Quantitative traits } \\
\hline 11 & 0.006 & SFU & Number & 12 & 0.048 & Кр & Number \\
\hline 13 & -0.119 & & Number & 14 & 0.009 & $\mathrm{At}^{0}$ & Number \\
\hline 15 & -0.058 & $\Delta \mathrm{t}^{0}$ & Number & 16 & -0.019 & v & Number \\
\hline 17 & -0.005 & $\Delta \mathrm{n}$. & Number & & & & \\
\hline
\end{tabular}

Algorithm of work with the introduced tables. Example: Discrete feature «sex» (code 1: male; 2: female) diagnosed by a method as factor having a statistically significant relationship with the classification variable GRUP_MI. Negative regression coefficient $(-0.419)$ indicates that the maximum gradation of this factor (2: female) reduces the probability of applying a particular observation to group 1: «young». The converse proposition is also true: in the group of patients belonging to the young age, there are statistically more men. Statistics 
coefficient Wald Chi-Square which is high enough (22.842) indicates that this factor affects the total probability. And so on.

The aim of logistic regression method is always twofold. On the one hand, a prediction whether of not the event will occur $(P=1)$ can be made on its basis. If $P>.5$ it is considered that the event will occur, $\mathrm{P}<.5$ it is considered that the event will not occur. On the other hand, (and in the present research it is more important), we obtain the evaluation of the multidimensional relationships between the dependent variable (GRUP_MI) and the predictors involved in the analysis. However, if the dependent variable is not a "binary", the interpretation of the results causes substantial problems. An in-depth analysis of the distribution of frequencies in the contingency tables' columns between a pair of quality (discrete) features is made in the solution part. The obtained results allow establishing the structure of the revealed relationship at the level of the combinations of individual gradations of both features.

\subsection{Discrete Feature CVA "Sex"}

Components of the mathematical model (Table 4;5): Regression Coefficient $<0$ : $\left(B_{1}\right)=-$ 0,419 ; values $X_{1}$ : $(1$ - male; 2 - female), permit stating a working hypothesis: In the analyzed population men statistically died from vascular accidents at a younger age than women.

Arrangement of frequencies of the classification variable GRUP_MI by gradations of discrete feature "Sex" with the calculation of standardized assessments is given in Table 6.

Table 6. Contingency table GRUP_MI * "Sex"

\begin{tabular}{|c|c|c|c|c|c|c|c|}
\hline \multirow[t]{2}{*}{ Sex } & & \multicolumn{5}{|l|}{ Group } & \multirow[t]{2}{*}{ Total } \\
\hline & & "young» & «middl & 》elderly» & «senile» & «long-livers» & \\
\hline \multirow[t]{3}{*}{ Male } & frequency & 19 & 115 & 273 & 121 & 1 & 529 \\
\hline & $\%$ & $55,9 \%$ & $57.5 \%$ & $50.6 \%$ & $34.0 \%$ & $20.0 \%$ & $46.6 \%$ \\
\hline & St. Estimate & $.8^{*}$ & $2.3^{*}$ & $1.3^{*}$ & -3.5 & -.9 & \\
\hline \multirow{3}{*}{ Female } & frequency & 15 & 85 & 267 & 235 & 4 & 606 \\
\hline & $\%$ & $44.1 \%$ & $42.5 \%$ & $49.4 \%$ & $66.0 \%$ & $80.0 \%$ & $53.4 \%$ \\
\hline & St. Estimate & -.7 & -2.1 & -1.3 & $3.3^{*}$ & $.8^{*}$ & \\
\hline \multirow[t]{2}{*}{ Total } & frequency & 34 & 200 & 540 & 356 & 5 & 1135 \\
\hline & $\%$ & $100 \%$ & $100 \%$ & $100 \%$ & $100 \%$ & $100 \%$ & $100 \%$ \\
\hline
\end{tabular}

During the analysis of the pairing contingency tables the value of the total Chi-square test $\mathrm{X} 2$ $=38.295$ (at the value of the achieved significance level of $P<.001$, i.e. there is a statistically confirmed connection between the two features). The connection force between this pair of qualitative features (Cramer 's V) equals .184. Comparing the dynamics of actual and expected frequencies (expressed as a ratio "Standardized Estimate"), it is easy to see that women show a positive statistically significant association for the group "senile" and negative statistically significant correlation for groups of "young», «middle-aged» and «elderly». Forthemen - vice-versa.

The link between the two analyzed featured is proved, the hypothesis is confirmed. 


\subsection{Discrete Feature CVA "Type of Cerebral Stroke"}

Components of the mathematical model (Table 4;5): Regression Coefficient $<0$ : $\left(B_{2}\right)=-$ 0,155 ; values $X_{2}$ : (1 - haemorrhagic; 2 - ischemic), permit stating a working hypothesis: Haemorrhagic type of the CS is statistically more frequent among the people of younger age. For older people ischemic type of the CS is more typical.

Arrangement of frequencies of classification variable GRUP_MI by gradations of discrete feature "CS type" (gradation: haemorrhagic - ischemic), with the calculation of standardized assessments is given Table 7 .

Table 7. Contingency table GRUP_MI * "cerebral stroke type"

\begin{tabular}{|c|c|c|c|c|c|c|c|}
\hline \multicolumn{2}{|c|}{ Type of cerebral stroke } & \multicolumn{5}{|l|}{ Group } & \multirow[t]{2}{*}{ Total } \\
\hline & & "young» & «middle» & «elderly» & «senile» & $\begin{array}{l}\text { «long- } \\
\text { livers" }\end{array}$ & \\
\hline Ischemic & $\begin{array}{l}\text { frequency } \\
\% \\
\text { St Estimate }\end{array}$ & $\begin{array}{l}12 \\
35.3 \% \\
-2.2\end{array}$ & $\begin{array}{l}97 \\
48.5 \% \\
-3.2\end{array}$ & $\begin{array}{l}367 \\
68.0 \% \\
3^{*}\end{array}$ & $\begin{array}{l}278 \\
78.1 \% \\
2.6^{*}\end{array}$ & $\begin{array}{l}4 \\
80.0 \% \\
4^{*}\end{array}$ & $\begin{array}{l}758 \\
66.8 \%\end{array}$ \\
\hline Hemorrhagic & $\begin{array}{l}\text { frequency } \\
\%\end{array}$ & $\begin{array}{l}22 \\
64.7 \%\end{array}$ & $\begin{array}{l}103 \\
51.5 \%\end{array}$ & $\begin{array}{l}173 \\
32.0 \%\end{array}$ & $\begin{array}{l}78 \\
21.9 \%\end{array}$ & $\begin{array}{l}1 \\
20.0 \%\end{array}$ & $\begin{array}{l}377 \\
33.2 \%\end{array}$ \\
\hline Total & $\begin{array}{l}\text { St. Estimate } \\
\text { frequency } \\
\%\end{array}$ & $\begin{array}{l}3.2^{*} \\
34 \\
100 \%\end{array}$ & $\begin{array}{l}4.5^{*} \\
200 \\
100 \%\end{array}$ & $\begin{array}{l}-.5 \\
540 \\
100 \%\end{array}$ & $\begin{array}{l}-3.7 \\
356 \\
100 \%\end{array}$ & $\begin{array}{l}-.5 \\
5 \\
100 \%\end{array}$ & $\begin{array}{l}1135 \\
100 \%\end{array}$ \\
\hline
\end{tabular}

During the analysis of the pairing contingency tables the value of the total Chi-square test $X^{2}$ $=66.585$ (at the value of the achieved significance level of $P<.001$, i.e. there is a statistically confirmed connection between the two features). The connection force between this pair of qualitative features (Cramer`s V) equals .242.

Immediately according to the ischemic type of CS: the groups "elderly", "senile" and "longlivers" demonstrate a positive statistically significant association with the specified CS subtype. Further analysis with differentiation between classes of ischemic stroke clearly demonstrates that the observed association is mainly conditioned by high content of class "non-ATB" in these groups (Chi-square test X2 = 92,008; $(R<.001)$, Cramer 's $V=.142$ ).

According to the haemorrhagic type of CS: positive statistically significant association was detected with the groups "young" and "middle-aged". Further analysis with differentiation between different classes of haemorrhagic stroke showed that the discovered association is mainly conditioned by high content of the hematomas with the breakthrough of blood into the ventricles of the brain in the indicated classes (Chi-square test $X^{2}=92.008(P<.001)$, Cramer`s V = .142).

The link between the two analyzed featured is proved, the hypothesis is confirmed and is formulated in the extended form:: haemorrhagic type of CS (especially class of hematomas with the breakthrough of blood into the ventricles of the brain) is statistically more frequent among people of younger age (groups 'young" and "middle-aged"). For older people (groups "elderly", "senile" and "long-livers") ischemic type of the CS, and especially non-ATB class, is more typical. 


\subsection{Discrete Feature CVA "Death in the $1^{\text {st }}$ day"}

Components of the mathematical model (Table 4;5): Regression Coefficient $>0:\left(B_{3}\right)=$ 0.373 ; values $\mathrm{X}_{3}$ : $(0$ - survived; 1 - died), permit stating a working hypothesis: Patients of younger age who suffered from vascular accident were statistically more likely to die within the first day after the onset of CS compared to the patients of older age groups.

Arrangement of frequencies classification variable GRUP_MI by gradations of discrete feature "Death during the first day" with the calculation of standardized assessments is shown in Table 8.

Table 8. Contingency table GRUP_MI * "death in the $1^{\text {st }}$ day"

\begin{tabular}{|c|c|c|c|c|c|c|c|}
\hline \multicolumn{2}{|c|}{ Death in the $1^{\text {st }}$ day } & \multicolumn{5}{|l|}{ Group } & \multirow[t]{2}{*}{ Total } \\
\hline & & "young" & «middl & 》elderly» & "senile» & $\begin{array}{l}\text { «long- } \\
\text { livers» }\end{array}$ & \\
\hline Survived & $\begin{array}{l}\text { frequency } \\
\% \\
\text { St. Estimate }\end{array}$ & $\begin{array}{l}26 \\
76.5 \% \\
-.8\end{array}$ & $\begin{array}{l}169 \\
84.5 \% \\
-.7\end{array}$ & $\begin{array}{l}481 \\
89.1 \% \\
-.1\end{array}$ & $\begin{array}{l}334 \\
93.8 \% \\
.9^{*}\end{array}$ & $\begin{array}{l}5 \\
100.0 \% \\
.2^{*}\end{array}$ & $\begin{array}{l}1015 \\
89.4 \%\end{array}$ \\
\hline Died & $\begin{array}{l}\text { frequency } \\
\%\end{array}$ & $\begin{array}{l}8 \\
23.5 \%\end{array}$ & $\begin{array}{l}31 \\
15.5 \%\end{array}$ & $\begin{array}{l}59 \\
10.9 \%\end{array}$ & $\begin{array}{l}22 \\
6.2 \%\end{array}$ & $\begin{array}{l}0 \\
.0 \%\end{array}$ & $\begin{array}{l}120 \\
10.6 \%\end{array}$ \\
\hline Total & $\begin{array}{l}\text { St. Estimate } \\
\text { frequency } \\
\%\end{array}$ & $\begin{array}{l}2.3^{*} \\
34 \\
100 \%\end{array}$ & $\begin{array}{l}2.1^{*} \\
200 \\
100 \%\end{array}$ & $\begin{array}{l}.3^{*} \\
540 \\
100 \%\end{array}$ & $\begin{array}{l}-2.5 \\
356 \\
100 \%\end{array}$ & $\begin{array}{l}-.7 \\
5 \\
100 \%\end{array}$ & $\begin{array}{l}1135 \\
100 \%\end{array}$ \\
\hline
\end{tabular}

During the analysis of the pairing contingency tables the value of the total Chi-square test $\mathrm{X}^{2}$ $=19.101$ (at the value of the achieved significance level of $P<.001$, i.e. there is a statistically confirmed connection between the two features). The connection force between this pair of qualitative features (Cramer's V) equals .130. Positive statistically significant association with the dependent variable (value "died") was revealed for the groups "young" and "middle". For the groups "senile" and "long-livers" the association is negative.

The link between the two analyzed featured is proved, the hypothesis is confirmed.

\subsection{Discrete Feature RF "Hypertension"}

Components of the mathematical model (Table 4;5): Regression Coefficient $>0:\left(B_{4}\right)=$ 0.562 ; values $\mathrm{X}_{4}$ : $(0$ - healthy; 1 - ill), permit stating a working hypothesis: Patients of the younger age who died of CS were statistically more likely to have hypertension in anamnesis.

Arrangement of frequencies classification variable GRUP_MI by gradations of discrete feature "Hypertension", with the calculation of standardized assessments is shown in Table 9. 
Table 9. Contingency table GRUP_MI * "hypertension"

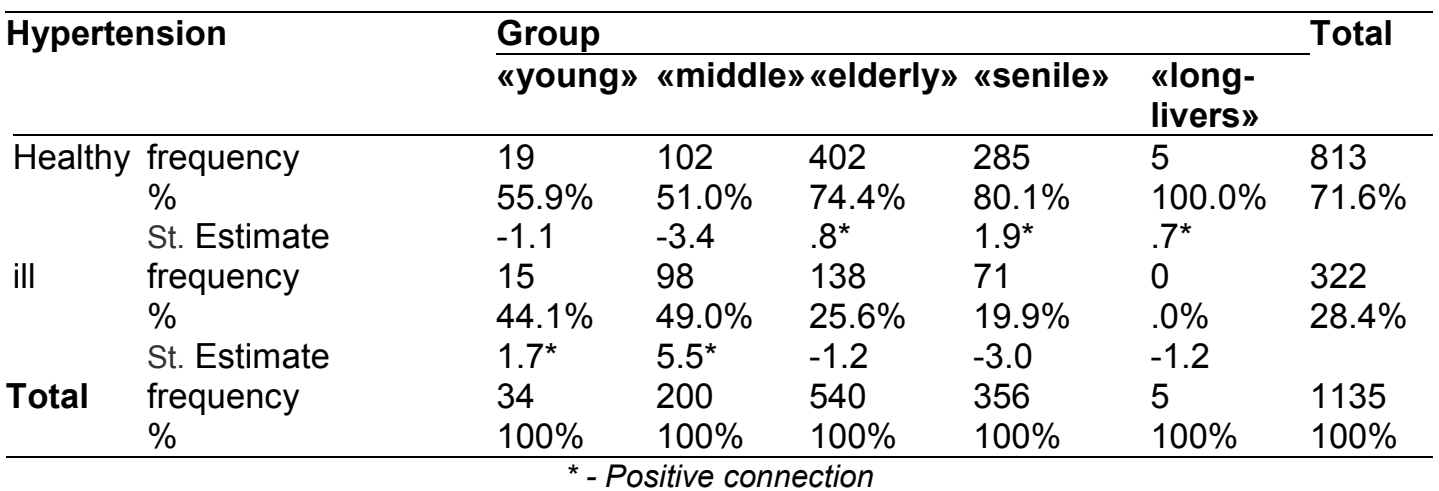

During the analysis of the pairing contingency tables the value of the total Chi-square tests: $\mathrm{X}^{2}=62.559$ (at the value of the achieved significance level of $P<.001$, i.e. there is a statistically confirmed connection between the two features). The connection force between this pair of qualitative features (Cramer's V) equals .235. Positive statistically significant association with the dependent variable (value "ill") was revealed for the groups "young" and "middle". Forthegroups "elderly", "senile" and "long-livers" the association is negative.

The link between the two analyzed featured is proved, the hypothesis is confirmed.

\subsection{Discrete Feature RF “Alcoholism”}

Components of the mathematical model (Table 4;5): Regression Coefficient $>0:\left(B_{5}\right)=$ 0.995; values $X_{5}$ : $(0$ - healthy; 1 - ill), permit stating a working hypothesis: Patients of the younger age who died of CS were statistically more likely to have alcoholism in anamnesis.

Arrangement of frequencies classification variable GRUP_MI by gradations of discrete feature "alcoholism", with the calculation of standardized assessments is shown in Table 10.

Table 10. Contingency table GRUP_MI * "Alcoholism”

\begin{tabular}{|c|c|c|c|c|c|c|c|}
\hline \multicolumn{2}{|c|}{ Alcoholism } & \multicolumn{5}{|l|}{ Group } & \multirow[t]{2}{*}{ Total } \\
\hline & & "young" & «middl & " "elderly» & "senile» & $\begin{array}{l}\text { "long- } \\
\text { livers» }\end{array}$ & \\
\hline Healthy & $\begin{array}{l}\text { frequency } \\
\% \\
\text { St. Estimate }\end{array}$ & $\begin{array}{l}29 \\
85.3 \% \\
-.4\end{array}$ & $\begin{array}{l}170 \\
85.0 \% \\
-1.1\end{array}$ & $\begin{array}{l}490 \\
90.7 \% \\
-.3\end{array}$ & $\begin{array}{l}352 \\
98.9 \% \\
1.3^{*}\end{array}$ & $\begin{array}{l}5 \\
100.0 \% \\
.2^{*}\end{array}$ & $\begin{array}{l}1046 \\
92.2 \%\end{array}$ \\
\hline ill & $\begin{array}{l}\text { frequency } \\
\%\end{array}$ & $\begin{array}{l}5 \\
14.7 \%\end{array}$ & $\begin{array}{l}30 \\
15.0 \%\end{array}$ & $\begin{array}{l}50 \\
9.3 \%\end{array}$ & $\begin{array}{l}4 \\
1.1 \%\end{array}$ & $\begin{array}{l}0 \\
.0 \%\end{array}$ & $\begin{array}{l}89 \\
7.8 \%\end{array}$ \\
\hline Total & $\begin{array}{l}\text { St. Estimate } \\
\text { frequency } \\
\%\end{array}$ & $\begin{array}{l}1.4^{*} \\
34 \\
100 \%\end{array}$ & $\begin{array}{l}3.6^{*} \\
200 \\
100 \%\end{array}$ & $\begin{array}{l}1.2^{*} \\
540 \\
100 \%\end{array}$ & $\begin{array}{l}-4.5 \\
356 \\
100 \%\end{array}$ & $\begin{array}{l}-.6 \\
5 \\
100 \%\end{array}$ & $\begin{array}{l}1135 \\
100 \%\end{array}$ \\
\hline
\end{tabular}

During the analysis of the pairing contingency tables the value of the total Chi-square test: $X^{2}=40.559$ (at the value of the achieved significance level of $P<.001$, i.e. there is a 
statistically confirmed connection between the two features). The connection force between this pair of qualitative features (Cramer's V) equals .189. Positive statistically significant association with the dependent variable (value "ill") was revealed for the groups "young", "middle" and "elderly". For the groups "senile" and "long-livers" the association is negative.

The link between the two analyzed featured is proved, the hypothesis is confirmed.

\subsection{Discrete Feature RF "Atherosclerosis"}

Components of the mathematical model (Table 4;5): Regression Coefficient $<0$ : $\left(\mathrm{B}_{6}\right)=-$ 0.244 ; values $X_{6}$ : $(0-(0-2$ stage $)$; 1 - (3-4 stage $)$ ), permit stating a working hypothesis: Patients of the younger age who died of CS were statistically more likely to have in anamnesis atherosclerosis in a milder form than the patients of the older age groups, or not to have it at all.

Arrangement of frequencies classification variable GRUP_MI by gradations of discrete feature "atherosclerosis", with the calculation of standardized assessments is shown in Table 11.

Table 11. Contingency table GRUP_MI * "Atherosclerosis"

\begin{tabular}{|c|c|c|c|c|c|c|c|}
\hline \multicolumn{2}{|c|}{ Atherosclerosis } & \multicolumn{5}{|l|}{ Group } & \multirow[t]{2}{*}{ Total } \\
\hline & & "young» & «middl & "elderly» & "senile» & $\begin{array}{l}\text { "long- } \\
\text { livers» }\end{array}$ & \\
\hline $0-2$ stage & $\begin{array}{l}\text { frequency } \\
\% \\
\text { St. Estimate }\end{array}$ & $\begin{array}{l}27 \\
79.4 \% \\
11.1^{*}\end{array}$ & $\begin{array}{l}60 \\
30.0 \% \\
7.1^{*}\end{array}$ & $\begin{array}{l}46 \\
8.5 \% \\
-2.5\end{array}$ & $\begin{array}{l}7 \\
2.0 \% \\
-5.6\end{array}$ & $\begin{array}{l}0 \\
.0 \% \\
-.8\end{array}$ & $\begin{array}{l}140 \\
12.3 \%\end{array}$ \\
\hline 3-4 stage & $\begin{array}{l}\text { frequency } \\
\%\end{array}$ & $\begin{array}{l}7 \\
20.6 \%\end{array}$ & $\begin{array}{l}140 \\
70.0 \%\end{array}$ & $\begin{array}{l}494 \\
91.5 \%\end{array}$ & $\begin{array}{l}349 \\
98.0 \%\end{array}$ & $\begin{array}{l}5 \\
100.0 \%\end{array}$ & $\begin{array}{l}995 \\
87.7 \%\end{array}$ \\
\hline & St. Estimate & -4.2 & -2.7 & $.9^{*}$ & $2.1^{*}$ & $.3^{*}$ & \\
\hline Total & $\begin{array}{l}\text { frequency } \\
\%\end{array}$ & $\begin{array}{l}34 \\
100 \%\end{array}$ & $\begin{array}{l}200 \\
100 \%\end{array}$ & $\begin{array}{l}540 \\
100 \% \\
\end{array}$ & $\begin{array}{l}356 \\
100 \% \\
\end{array}$ & $\begin{array}{l}5 \\
100 \%\end{array}$ & $\begin{array}{l}1135 \\
100 \%\end{array}$ \\
\hline
\end{tabular}

During the analysis of the pairing contingency tables the value of the total Chi-square test: $X^{2}=242.558$ (at the value of the achieved significance level of $P<.001$, i.e. there is a statistically confirmed connection between the two features). The connection force between this pair of qualitative features (Cramer's V) equals .462 .

The link between the two analyzed featured is proved, the hypothesis is confirmed.

\subsection{Discrete Feature RF "Coronary Heart Disease"}

Components of the mathematical model (Table 4;5): Regression Coefficient $<0$ : $\left(B_{7}\right)=-$ 0.240 ; values $X_{7}$ : $(0-$ healthy; 1 - ill), permit stating a working hypothesis: Patients of the younger age who died of CS were statistically more likely not to have coronary heart disease in anamnesis unlike the patients of older age groups.

Arrangement of frequencies classification variable GRUP_MI by gradations of discrete feature «ИБС», with the calculation of standardized assessments is shown in Table 12. 
Table 12. Contingency table GRUP_MI * "Coronary heart disease"

\begin{tabular}{|c|c|c|c|c|c|c|c|}
\hline \multicolumn{2}{|c|}{ Coronary heart disease } & \multicolumn{5}{|l|}{ Group } & \multirow[t]{2}{*}{ Total } \\
\hline & & "young» & «middl & "elderly» & «senile» & $\begin{array}{l}\text { "long- } \\
\text { livers" }\end{array}$ & \\
\hline Healthy & $\begin{array}{l}\text { frequency } \\
\% \\
\text { St. Estimate }\end{array}$ & $\begin{array}{l}21 \\
61.8 \% \\
8.0^{*}\end{array}$ & $\begin{array}{l}52 \\
26.0 \% \\
5.2^{*}\end{array}$ & $\begin{array}{l}57 \\
10.6 \% \\
-1.4\end{array}$ & $\begin{array}{l}15 \\
4.2 \% \\
-4.5\end{array}$ & $\begin{array}{l}0 \\
.0 \% \\
-.8\end{array}$ & $\begin{array}{l}145 \\
12.8 \%\end{array}$ \\
\hline ill & $\begin{array}{l}\text { frequency } \\
\%\end{array}$ & $\begin{array}{l}13 \\
38.2 \%\end{array}$ & $\begin{array}{l}148 \\
74.0 \%\end{array}$ & $\begin{array}{l}483 \\
89.4 \%\end{array}$ & $\begin{array}{l}341 \\
95.8 \%\end{array}$ & $\begin{array}{l}5 \\
100.0 \%\end{array}$ & $\begin{array}{l}990 \\
87.2 \%\end{array}$ \\
\hline Total & $\begin{array}{l}\text { St. Estimate } \\
\text { frequency } \\
\%\end{array}$ & $\begin{array}{l}-3.1 \\
34 \\
100 \%\end{array}$ & $\begin{array}{l}-2.0 \\
200 \\
100 \%\end{array}$ & $\begin{array}{l}.6^{*} \\
540 \\
100 \% \\
\end{array}$ & $\begin{array}{l}1.7^{*} \\
356 \\
100 \% \\
\end{array}$ & $\begin{array}{l}.3^{*} \\
5 \\
100 \% \\
\end{array}$ & $\begin{array}{l}1135 \\
100 \%\end{array}$ \\
\hline
\end{tabular}

During the analysis of the pairing contingency tables the value of the total Chi-square tests: $X^{2}=131.156$ (at the value of the achieved significance level of $P<.001$, i.e. there is a statistically confirmed connection between the two features). The connection force between this pair of qualitative features (Cramer's V) equals .340.

The link between the two analyzed featured is proved, the hypothesis is confirmed.

\subsection{Discrete Feature RF "Ciliary Arrhythmia"}

Components of the mathematical model (Table 4;5): Regression Coefficient $<0$ : $\left(B_{8}\right)=-$ 0.386; values $\mathrm{X}_{8}$ : $(0$ - healthy; 1 - ill), permit stating a working hypothesis: Patients of the younger age who died of CS statistically did not have ciliary arrhythmia in anamnesis unlike the patients of older age groups.

Arrangement of frequencies classification variable GRUP_MI by gradations of discrete feature "Ciliary arrhythmia", with the calculation of standardized assessments is shown in Table 13.

Table 13. Contingency table GRUP_MI * "ciliary arrhythmia"

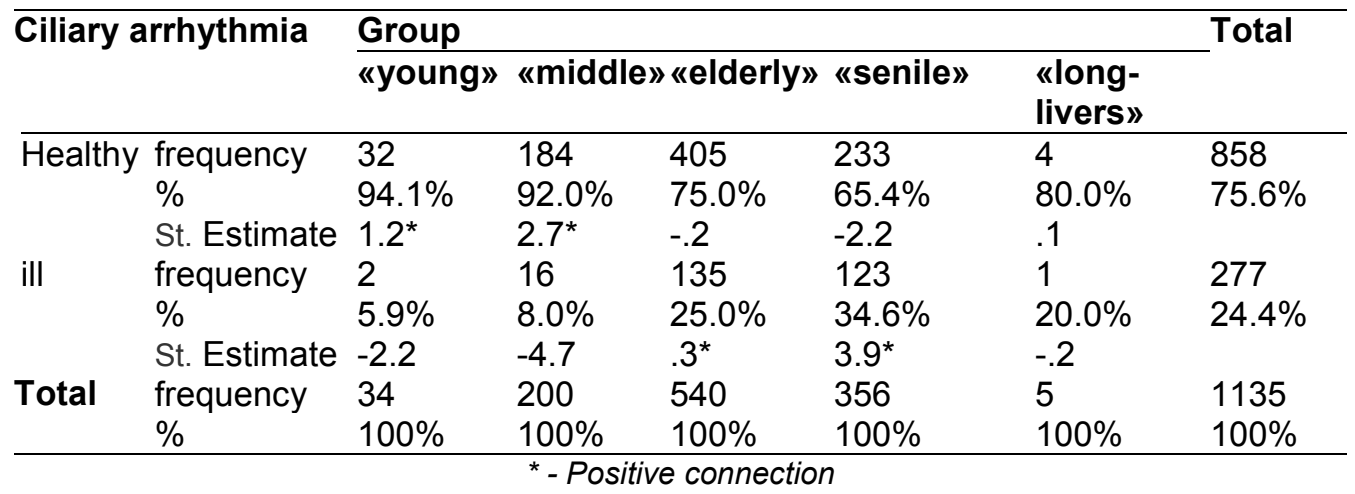

During the analysis of the pairing contingency tables the value of the total Chi-square tests: $X^{2}=55.516$ (at the value of the achieved significance level of $P<.001$, i.e. there is a 
statistically confirmed connection between the two features). The connection force between this pair of qualitative features (Cramer's V) equals .221.

The link between the two analyzed featured is proved, the hypothesis is confirmed.

\subsection{Discrete feature RF - "Secondary Arterial Hypertension"}

Components of the mathematical model (Table 4;5): Regression Coefficient $<0$ : $\left(B_{9}\right)=-$ 0.309 ; values $X_{9}$ : $(0$ - healthy; 1 - ill), permit stating a working hypothesis: Patients of the younger age who died of CS statistically did not have secondary arterial hypertension in anamnesis unlike the patients of older age groups.

Arrangement of frequencies classification variable GRUP_MI by gradations of discrete feature "Secondary arterial hypertension", with the calculation of standardized assessments is shown in Table 14.

Table 14. Contingency table GRUP_MI * "secondary arterial hypertension"

\begin{tabular}{|c|c|c|c|c|c|c|c|}
\hline \multirow{2}{*}{\multicolumn{2}{|c|}{$\begin{array}{l}\text { Secondary arterial } \\
\text { hypertension }\end{array}$}} & \multicolumn{5}{|l|}{ Group } & \multirow[t]{2}{*}{ Total } \\
\hline & & "young» & «middl & "elderly» & «senile» & $\begin{array}{l}\text { «long- } \\
\text { livers" }\end{array}$ & \\
\hline \multicolumn{2}{|c|}{ Healthy frequency } & 22 & 124 & 209 & 113 & 1 & 469 \\
\hline & $\%$ & $64.7 \%$ & $62.0 \%$ & $38.7 \%$ & $31.7 \%$ & $20.0 \%$ & $41.3 \%$ \\
\hline & St. Estimate & $2.1^{*}$ & $4.5^{\star}$ & -.9 & -2.8 & -.7 & \\
\hline \multirow[t]{2}{*}{ ill } & $\begin{array}{l}\text { frequency } \\
\%\end{array}$ & $\begin{array}{l}12 \\
35.3 \%\end{array}$ & $\begin{array}{l}76 \\
38.0 \%\end{array}$ & $\begin{array}{l}331 \\
61.3 \%\end{array}$ & $\begin{array}{l}243 \\
68.3 \%\end{array}$ & $\begin{array}{l}4 \\
80.0 \%\end{array}$ & $\begin{array}{l}666 \\
58.7 \%\end{array}$ \\
\hline & St. Estimate & -1.8 & -3.8 & $.8^{*}$ & $2.4^{*}$ & $.6^{*}$ & \\
\hline \multirow[t]{2}{*}{ Total } & frequency & 34 & 200 & 540 & 356 & 5 & 1135 \\
\hline & $\%$ & $100 \%$ & $100 \%$ & $100 \%$ & $100 \%$ & $100 \%$ & $100 \%$ \\
\hline
\end{tabular}

During the analysis of the pairing contingency tables the value of the total Chi-square tests: $X^{2}=58.877$ (at the value of the achieved significance level of $P<.001$, i.e. there is a statistically confirmed connection between the two features). The connection force between this pair of qualitative features (Cramer`s V) equals .228.

The link between the two analyzed featured is proved, the hypothesis is confirmed.

The established connection between the endogenous factors reflecting characteristics of CVA and the age of patients coincide with the official data and are familiar to every clinician $[11,12,13,14]$. This fact increases the credibility of the subsequent results of the method.

\subsection{EGF «SA Index»}

Components of the mathematical model (Table 4;5): Regression Coefficient $>0:\left(B_{10}\right)=$ 0.948; values $\mathrm{X}_{10}$ : $(0$ - low SA; 1 - high $\mathrm{SA})$, permit stating a working hypothesis: In the period of low SA death from CS was statistically more frequent among the patients of older age groups, whereas during the period of high SA - among younger patients. 
Arrangement of frequencies classification variable GRUP_MI by gradations of discrete feature "SA Index" with the calculation of standardized assessments is shown in Table 15.

Table 15. Contingency table GRUP_MI * "index of solar activity"

\begin{tabular}{|c|c|c|c|c|c|c|c|}
\hline \multicolumn{2}{|l|}{ SA Index } & \multicolumn{5}{|l|}{ Group } & \multirow[t]{2}{*}{ Total } \\
\hline & & "young" & «middle & «elderly» & «senile» & $\begin{array}{l}\text { "long- } \\
\text { livers" }\end{array}$ & \\
\hline of high SA & $\begin{array}{l}\text { frequency } \\
\% \\
\text { St. Estimate }\end{array}$ & $\begin{array}{l}19 \\
55.9 \% \\
-1.3\end{array}$ & $\begin{array}{l}137 \\
68.5 \% \\
-1.0\end{array}$ & $\begin{array}{l}378 \\
70.0 \% \\
-1.3\end{array}$ & $\begin{array}{l}310 \\
87.1 \% \\
2.7^{*}\end{array}$ & $\begin{array}{l}4 \\
80.0 \% \\
.1^{*}\end{array}$ & $\begin{array}{l}848 \\
74.7 \%\end{array}$ \\
\hline of low SA & $\begin{array}{l}\text { frequency } \\
\%\end{array}$ & $\begin{array}{l}15 \\
44.1 \%\end{array}$ & $\begin{array}{l}63 \\
31.5 \%\end{array}$ & $\begin{array}{l}162 \\
30.0 \%\end{array}$ & $\begin{array}{l}46 \\
12.9 \%\end{array}$ & $\begin{array}{l}1 \\
20.0 \%\end{array}$ & $\begin{array}{l}287 \\
25.3 \%\end{array}$ \\
\hline & St. Estimate & $2.2^{*}$ & $1.7^{*}$ & $2.2^{*}$ & -4.6 & -.2 & \\
\hline Total & $\begin{array}{l}\text { frequency } \\
\%\end{array}$ & $\begin{array}{l}34 \\
100 \%\end{array}$ & $\begin{array}{l}200 \\
100 \%\end{array}$ & $\begin{array}{l}540 \\
100 \%\end{array}$ & $\begin{array}{l}356 \\
100.0 \%\end{array}$ & $\begin{array}{l}5 \\
100 \%\end{array}$ & $\begin{array}{l}1135 \\
100 \%\end{array}$ \\
\hline
\end{tabular}

During the analysis of the pairing contingency tables the value of the total Chi-square tests: $\mathrm{X}^{2}=45.705$ (at the value of the achieved significance level of $P<.001$, i.e. there is a statistically confirmed connection between the two features). The connection force between this pair of qualitative features (Cramer's V) equals .201. Maximum contribution to the statistics $X^{2}$ is made by the intersection of line "high" (SA Index) and column "senile" (group) - negative connection of two features, and the line "high" (SA Index) and columns "young" and "elderly" (group) - positive connection of two features.

The link between the two analyzed featured is proved, the hypothesis is confirmed.

The descriptive statistics (mean, error of mean, variation coefficient) were assessed for all the identified quantitative features separately in subgroups formed by the feature GRUP_MI. These results permit to examine which of these attributes reached the maximum or minimum value in a particular group (observation group).

\subsection{EGF «SFU»}

SFU - solar radio emission flux at the frequency $2800 \mathrm{MHz}(10.7 \mathrm{~cm})$ [15]. Measure unit: in solar flux units (sfu), is the main indicator of solar activity and determines the level of radiation received by the Earth from the Sun. Solar radio flux has a direct impact on the degree of ionization and consequently the concentration of electrons in the ionosphere. Radio Astrophysical Observatory, Penticton, British Columbia (Canada), publishes the SFU value daily.

Components of the mathematical model (Table 4;5): Regression Coefficient $>0$ : $\left(\mathrm{B}_{11}\right)=$ 0.006; values $X_{11}$ : (Number), permit stating a working hypothesis: Increased solar activity indicated by the SFU index may serve as a direct death risk factor for patients of younger age.

The values of the parameter characterizing solar activity (SFU) accompanying the day of CS onset in the two groups of classification variable GRUP_MI were calculated. Total variability of the analyzed variable is divided into two components: intergroup (factorial), conditioned by 
the difference in groups (mean values), and intragroup (error of mean) conditioned by accidental emissions. Graphical demonstration of the descriptive statistics (Fig. 3).

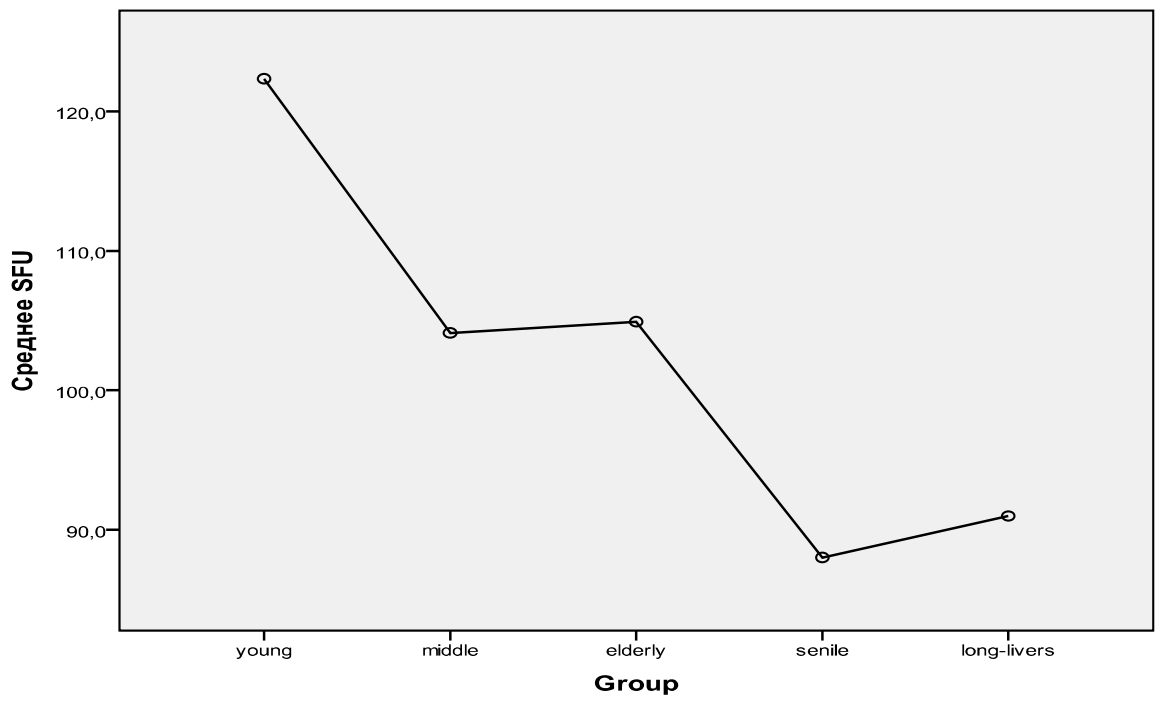

Fig. 3. Characteristic (mean) values of the radio emission flux on the wave of $10.7 \mathrm{~cm}$ (SFU) on the onset day of CS in patients of different age groups. On the abscissa axis - groups. The ordinate axis - index average value (SFU)

The conclusion about the difference between the mean values is made on the basis of the variance components analysis (comparing central group parameters). Increased radio flux values (SFU) (Fig. 3) were observed in the days of the CS onset among the young and middle-aged patients (Kruskal-Wallis test: $X 2=39.092(P<.001) \mathrm{c}$ ) relative to SFU values in the days of the CS onset among the patients of older ages.

The link between the two analyzed featured is proved, the hypothesis is confirmed.

\subsection{EGF «Kp»}

Kp - quasilogarithmic, planetary average daily geomagnetic activity index [16]. It is calculated as a mean value of $\mathrm{K}$-indices, detected by 13 geomagnetic observatories located between $44^{\circ}$ and $60^{\circ}$ northern and southern geomagnetic latitudes. It ranges between 0 and 9.

$$
\begin{aligned}
& \mathrm{Kp}<=2-\text { calm; } \\
& \mathrm{Kp}=(2-3) \text { - slightly disturbed; } \\
& \mathrm{Kp}=4-\text { disturbed; } \\
& \mathrm{Kp}=(5-6) \text { - magnetic storm; } \\
& \mathrm{Kp}>=7 \text { - large magnetic storm }
\end{aligned}
$$

Components of the mathematical model (Table 4;5): Regression Coefficient $>0:\left(B_{12}\right)=$ 0.048 ; values $X_{12}$ : (number), permit stating a working hypothesis: Increased geomagnetic activity indicated by the $\mathrm{Kp}$ index may serve as a direct death risk factor for patients of younger age. 
The values of the parameter characterizing geomagnetic activity (Kp index) accompanying the day of CS onset in the compared groups of classification variable GRUP_MI were calculated. Graphical demonstration of the descriptive statistics (Fig. 4).

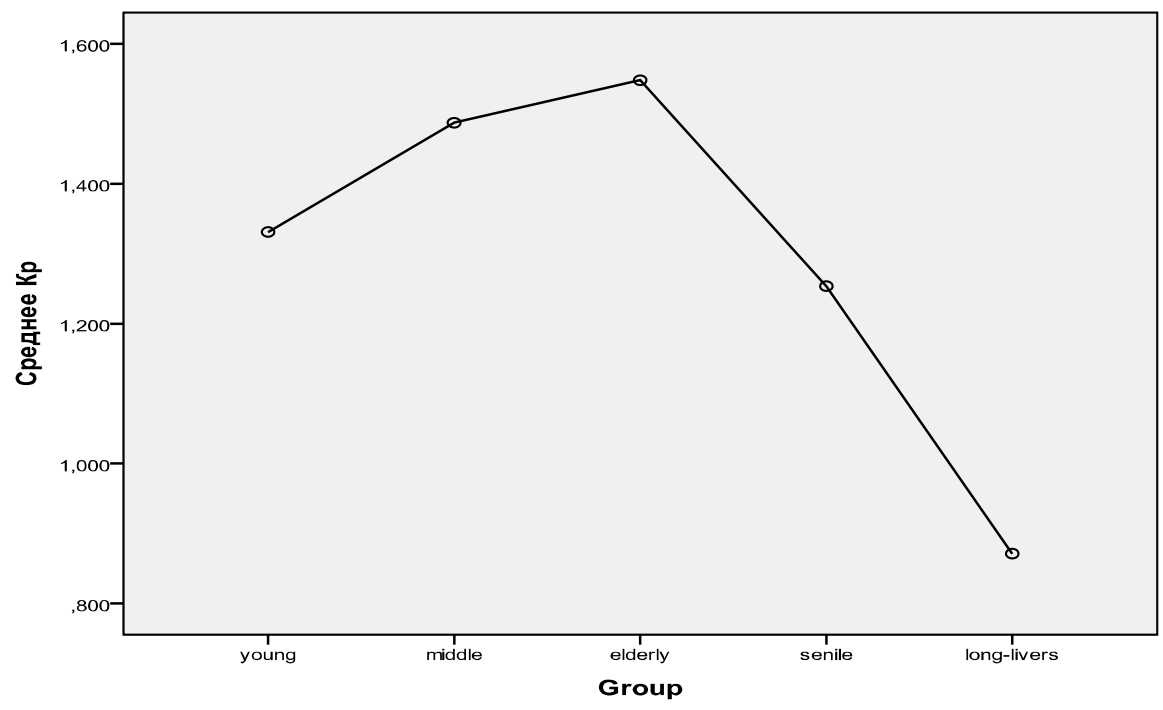

Fig. 4. Characteristic (mean) values of the geomagnetic activity (Kp) on the onset day of CS in patients of different age groups. On the abscissa axis - groups. The ordinate axis - Kp index average value

Variance components analysis (comparing central group parameters) showed that the value of Kruskal-Wallis test: $X^{2}=36.066$ (at the value of the achieved significance level of $P=.001$, the variance components analysis (comparing central group parameters)).

The link between the two analyzed featured is proved, the hypothesis is confirmed.

\subsection{EGF «Meteorological Pathogenicity Index»}

G.D.Latyshev and V.G.Boksha [17] proposed a clinical weather index (meteorological pathogenicity index (I)) to quantify the degree of irritant action of weather factors on the human body. It is made up of partial pathogenicity indices, reflecting weather dynamics during the day according to the changes of air temperature, humidity, wind speed, cloudiness, day to day changes in atmospheric pressure and temperature. (2), (3).

$$
\begin{aligned}
& I=I_{\mathrm{h}}+\mathrm{I}_{\mathrm{V}}+\mathrm{I}_{\mathrm{n}}+\mathrm{I}_{\Delta \mathrm{p}}+\mathrm{I}_{\Delta \mathrm{t}}+\mathrm{I}_{\mathrm{t}} \\
& I=10^{\frac{h-70}{20}}+0,2 v^{2}+0,06 n^{2}+0,06(\Delta p)^{2}+0,3(\Delta t)^{2}+I_{t}
\end{aligned}
$$

Here:

Ih - air humidity pathogenicity index; $\mathrm{h}$ - average daily relative humidity (\%);

Iv - wind pathogenicity index; $v$ - average daily wind $(\mathrm{m} / \mathrm{c})$;

In - cloudiness pathogenicity index determined by 11-point scale: 0 - corresponds to the complete absence of clouds, and 10 points - overcast; $n$ - cloudiness point; 


\section{c. 20}

$\Delta \mathrm{p}$ - pathogenicity index of day to day changes in atmospheric pressure; $\Delta \mathrm{p}-$ day to day changes in pressure $(\mathrm{hPa})$;

$\Delta t$ - pathogenicity index of day to day changes in temperature; $\Delta t-$ day to day changes in temperature $\left({ }^{\circ} \mathrm{C}\right)$;

It - air temperature pathogenicity index $\mathrm{It}=0.02(18-\mathrm{t})^{2}$ at $\mathrm{t}<=18^{\circ} \mathrm{C}$ and $\mathrm{It}=0.2(\mathrm{t}-18)$ at $\mathrm{t}>18^{\circ} \mathrm{C}$,

Depending on the value I the conditions are assessed as: I =0 - 9 -optimal conditions; I = 10 - 24 - irritant; I >24 - critical.

Components of the mathematical model (Table 4;5): Regression Coefficient < 0: $\left(\mathrm{B}_{13}\right)=-$ 0.119 ; values $\mathrm{X}_{13}$ : (number), permit stating a working hypothesis: Meteorological conditions with a high value of pathogenicity index (assessed as irritating or acute) can serve as an immediate death risk factor for the patients of older age groups.

The values of the weather factors irritating action on the human body (index I) accompanying the day of CS onset in the compared groups of classification variable GRUP_MI were calculated. Graphical demonstration of the descriptive statistics (Fig. 5).

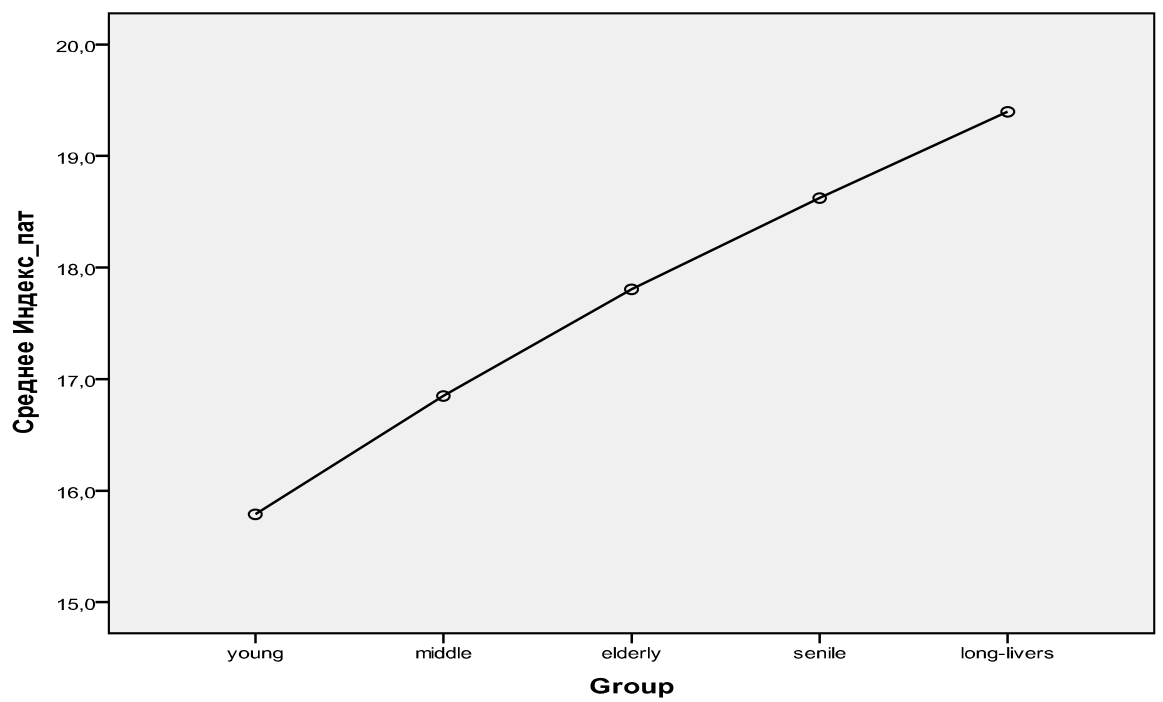

Fig. 5. Characteristic (mean) values of pathogenicity index (I) on the onset day of CS in patients of different age groups. On the abscissa axis - groups. The ordinate axis average value of the index I

Directly proportional dependence between the age of the patients and increased pathogenicity (Kruskal-Wallis test: $X^{2}=12.503(P=.014)$ is detected i.e. there is a statistically proved difference between the mean values). In other words with the increase of age the maximum of the meteopathic reactions is observed.

The adequacy of the indicator worked out exclusively for medical purposes must be admitted. Total meteorological pathogenicity index does not indicate the nature of the weather change, but only the extent of its irritating effect on the body. It was developed in 
the 1960s and, of course, at the time the authors did not have the arsenal of modern computational capabilities. The results of some recent research studies and studies of the past century aimed at identifying the links between the external factors and one or another disease are ambiguous and sometimes contradictory [18-36]. It is possible that the reason lies in the fact that medical statistical indicators correlate with indices characterizing the variability of the environment which were not foreseen by their creators for such manipulations. There is an opinion in the medical community, which is supported by the authors of this article, that there is a certain lack of indices characterizing the variability of the environment developed specially for demonstrating the degree of severity of the impact on biological systems.

The link between the two analyzed featured is proved, the hypothesis is confirmed.

\subsection{EGF «Daily Temperature Amplitude» (A t ${ }^{0}$ )}

The absolute value of the temperature variability during the day is very important for medical evaluation of the air temperature. The optimal value of the parameter under which there is a minimum meteotropic reactions: variability $\mathrm{T}^{0}: 0^{\circ} \mathrm{C} /$ day.

Components of the mathematical model (Table 4;5): Regression Coefficient $>0:\left(B_{14}\right)=$ 0.009 ; values $X_{14}$ : (number), permit stating a working hypothesis: High values of daily temperature range can serve as an immediate death risk factor for the patients of younger age groups.

The values of daily temperature range $\left(\mathrm{At}^{0}\right)$ accompanying the day of $\mathrm{CS}$ onset in the compared groups of classification variable GRUP_MI were calculated. Graphical demonstration of the descriptive statistics (Fig. 6).

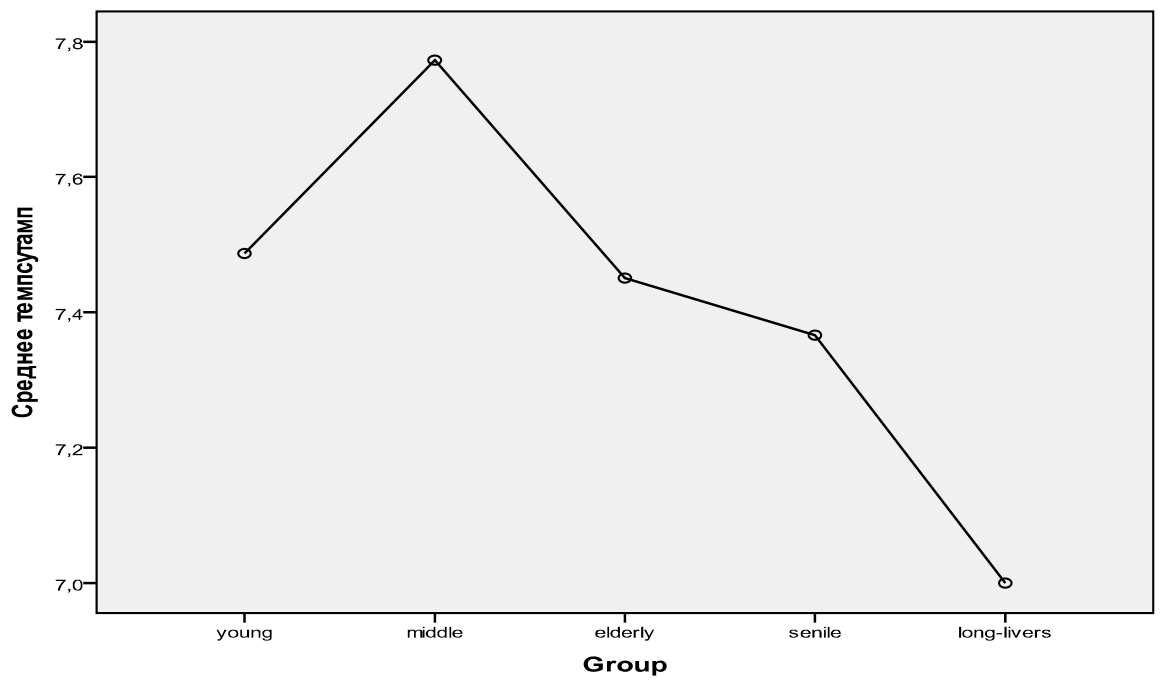

Fig. 6. Characteristic (mean) values of daily temperature range $\left(\mathrm{At}^{\mathrm{v}}\right)$ on the onset day of CS in patients of different age groups. On the abscissa axis - groups. The ordinate axis -average value of the index $\mathrm{At}^{\mathrm{O}}$ 
The analysis of variance components (comparison of the central parameters of the groups) showed that the value of Kruskal-Wallis test: $X^{2}=11.152$ (at the value of the achieved significance level of $P=.025$, i.e. there is a statistically confirmed difference between the average).

The link between the two analyzed featured is proved, the hypothesis is confirmed.

\subsection{EGF «Day to Day Changes in Temperature» $\left(\Delta \mathbf{t}^{0}\right)$}

Parameter optimum value at which the metetropic reactions are minimal: changeability $\mathrm{T}^{0}$ : $0^{\circ} \mathrm{C} /$ day.

Components of the mathematical model (Table 4;5): Regression Coefficient $<0$ : $\left(B_{15}\right)=-$ 0.058 ; values $X_{15}$ : (nuber), permit stating a working hypothesis: High values of day-to-day changes in temperature can serve as immediate death risk factor for the elderly patients.

The values of day-to-day change in temperature parameter $\left(\Delta t^{0}\right)$ accompanying the day of CS onset in the compared groups of classification variable GRUP_MI were calculated. Graphical demonstration of the descriptive statistics. (Fig. 7).

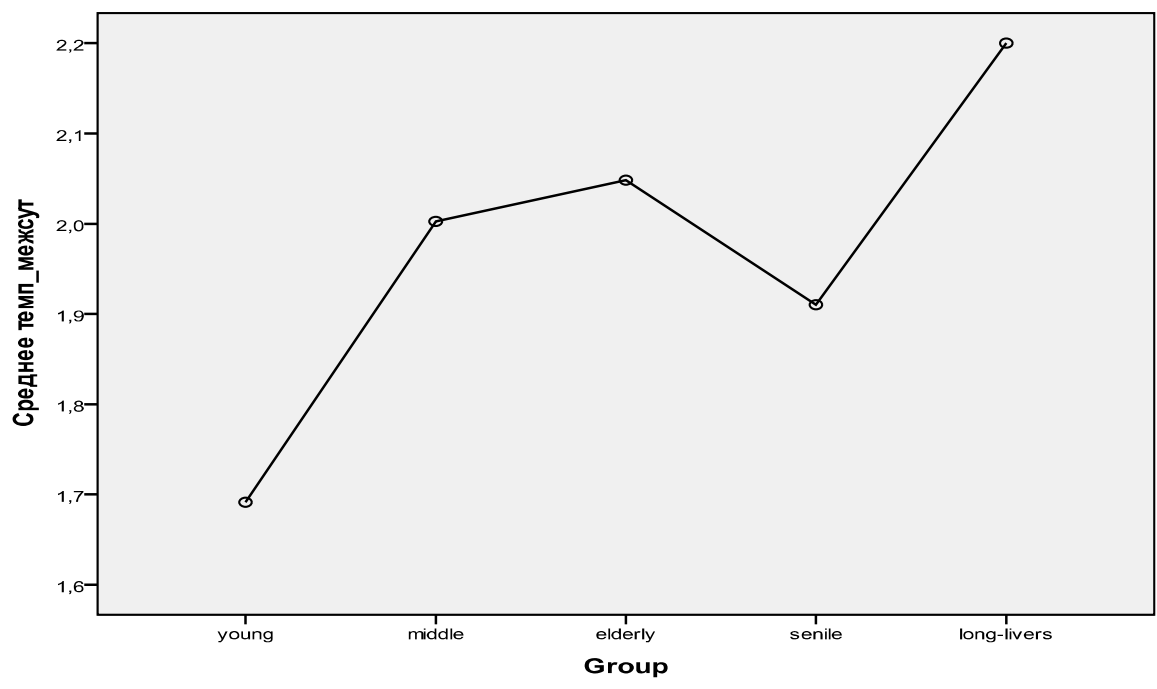

Fig. 7. Characteristic (mean) values of day-to-day change in temperature $\left(\Delta t^{0}\right)$ on the onset day of CS in patients of different age groups. On the abscissa axis - groups. The ordinate axis -average value of the index $\Delta t^{0}$

The analysis of variance components (comparison of the central parameters of the groups) showed that the value of Kruskal-Wallis test: $X^{2}=11.010$ (at the value of the achieved significance level of $P=.026$, i.e. there is a statistically confirmed difference between the average).

The link between the two analyzed featured is proved, the hypothesis is confirmed. 


\subsection{EGF «Average Daily Wind Speed» (v)}

Parameter optimum value at which the metetropic reactions are minimal: wind speed: $0 \mathrm{~m} / \mathrm{c}$. Components of the mathematical model (Table 4;5): Regression Coefficient < 0: $\left(B_{16}\right)=-$ 0.058 ; values $X_{16}$ : (nuber), permit stating a working hypothesis: High values of average daily wind speed can serve as immediate death risk factor for the elderly patients.

The values of average daily wind speed parameter ( $v$ ) accompanying the day of CS onset in the compared groups of classification variable GRUP_MI were calculated. Graphical demonstration of the descriptive statistics (Fig. 8)

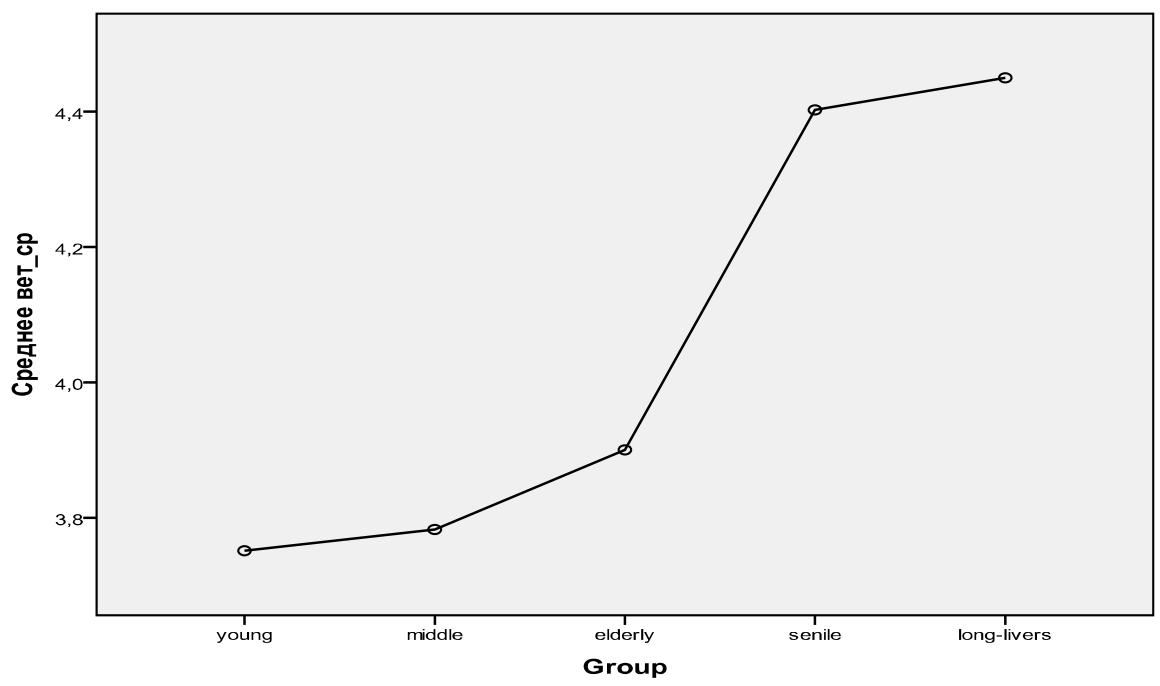

Fig. 8. Characteristic (mean) values of average daily wind speed (v) on the onset day of CS in patients of different age groups. On the abscissa axis - groups. The ordinate axis -average value of the index ( $v$ )

The analysis of variance components (comparison of the central parameters of the groups) showed that the value of Kruskal-Wallis test: $X^{2}=34.002$ (at the value of the achieved significance level of $P<.001$, i.e. there is a statistically confirmed difference between the average).

The link between the two analyzed featured is proved, the hypothesis is confirmed.

\subsection{EGF «Day to Day Changes in Cloudiness» $(\Delta \mathrm{n})$}

Parameter optimum value at which the metetropic reactions are minimal: cloudiness: 0 points.

Components of the mathematical model (Table 4;5): Regression Coefficient $<0$ : $\left(B_{17}\right)=-$ 0.005 ; values $X_{17}$ : (number), permit stating a working hypothesis: High values of day to day change in cloudiness can serve as immediate death risk factor for the elderly patients. 
The values of day to day changes in cloudiness parameter $(\Delta n)$ accompanying the day of CS onset in the compared groups of classification variable GRUP_MI were calculated. Graphical demonstration of the descriptive statistics (Fig. 9).

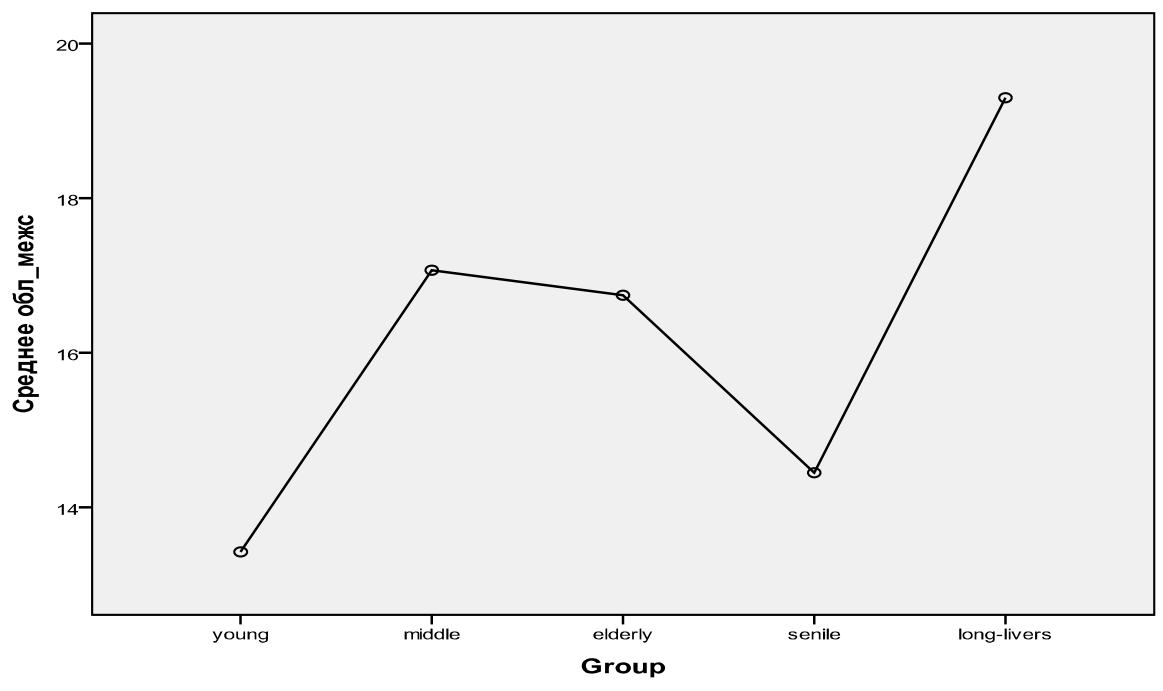

Fig. 9. Characteristic (mean) values of day to day changes in cloudiness ( $\Delta n$ ) on the onset day of CS in patients of different age groups. On the abscissa axis - groups. The ordinate axis -average value of the index $\Delta n$

The analysis of variance components (comparison of the central parameters of the groups) showed that the value of Kruskal-Wallis test: $X^{2}=9.931$ (at the value of the achieved significance level of $P=.042$, i.e. there is a statistically confirmed difference between the average).

The link between the two analyzed featured is proved, the hypothesis is confirmed.

\section{CONCLUSION}

Among the patients of the young and middle age CS percent of the total CVA amount - 3\% and $17.6 \%$ respectively, statistically often death resulted from severe somatic diseases associated with alcohol and hard drugs. These were mainly the patients suffering from hypertension. Characteristic CS type - hemorrhagic (especially hematoma class with blood breakthrough into the brain ventricles) with a tendency to stem localization. Severe course of disease with frequent deaths in the 1st day are typical. The average survival period after the onset of CS is 3-5 days.

The highest death rate is observed among the elderly patients $(47.6 \%$ of the total amount of CS), as the patients of senile age (31.4\% correspondingly), where along with primary hypertension appeared patients with secondary arterial hypertension. Atherosclerosis of the 3-4 stage and heart diseases in the form of ciliary arrhythmia and coronary heart disease were most frequent. Characteristic CS type - ischemic (especially non-atherothrombotic class). Death during the 1 st day was statistically less likely. The average survival period after the onset of CS is 8-10 days. 
The conducted research has clearly demonstrated that geogeliomagnetic and meteorological factors affect the probability of death in patients who belong to different age groups and suffered from CS in the study region. For the patients of young and middle age the effect is mostly associated with high solar and geomagnetic activity and, consequently, higher values of the indices SFU - solar radio flux and Kp - the index of geomagnetic activity. Among the patients of elderly and senile age maximum meteotropic reactions occur with intensification of wind and sudden changes in air temperature and cloudiness (contrasting weather patterns change, quick change of air masses with different thermal properties), which was confirmed statistically significant association. Directly proportional relationship between the age of the patients and increasing values of the pathogenicity index is observed, i.e. as the age increases the maximum of meteopathic reactions is reached.

The developed model of analysis and evaluation of mortality from CS under the influence of the studied factors can serve as part of prevention activities carried out by the health services in order to reduce mortality from CVA. The problem of prevention of death from CVA as well as from other cardiovascular diseases can be solved only by the interaction of the doctor, the patient and the society. In this regard in addition to pharmaceutical prevention of CS more educational activities aimed at reducing the CS risk factors identified for each individual should be carried out. Identified characteristic dependencies from of the changes of weather- and helio-factors may be taken into account in the therapeutic approach by reducing the physical and psychological stress and drug therapy dose adjustment. For prevention of CVA the values pathogenicity index should be calculated according to the short-term weather forecast. Afterwards this information must be communicated to each patient in order to prevent the occurrence new risks, including by the patients on one's own.

\section{CONSENT}

The authors inform that the research material is impersonal. It was handled for research purposes and these actions do not fall under the restrictions of the Federal Law of the Russian Federation No 152-FZ of 27.07.2006 "On Personal Data". Consent of the personal data subject is not required (clause.6, part 2, p.3). (Link: http://www.rg.ru/2006/07/29/personaljnye-dannye-dok.html)

\section{ETHICAL APPROVAL}

Not applicable.

\section{ACKNOWLEDGEMENTS}

The authors express their gratitude to the head of pathoanatomical department Y.G. Kirichenko, the head of neurological department O.G. Stakanova from the Municipal Hospital № 1 of Rostov-on-Don, for the research materials; to the associate professor of the Computer Science Department, Tomsk State University, Ph.D., V.P. Leonov for good-quality statistical data analysis.

\section{COMPETING INTERESTS}

The Authors disclose no financial or personal relationships with other people or organizations that could inappropriately influence their work. 


\section{REFERENCES}

1. Suslin ZA, Varyakin $Y Y$, Vereshchagin NV. Vascular diseases of the brain. Epidemiology. Fundamentals of prevention. MED press-Inform. 2006;C 255. Russian language.

2. Varakin YY, Gornostaeva GV, Manvel JI. The prevalence of different forms of cerebrovascular disease in the population of working age. Journal of Neurology and Psychiatry. SS Korsakov, the application "Stroke". 2003;9:112. Russian language.

3. Regional Long-term Target Program. Development of Health of the Rostov region in 2010-2013 years. p.9.5 c.35 [Online], Apr. 20:2013. Available: http://minzdrav.donland.ru/ Russian language.

4. Kadykov AS, Kalashnikova LA, Shahparonov NV. Stroke and others at a young age. Herald Practical Nevrologii. 1996;2:5-7. Russian language.

5. Vereshchagin NV, Piradov MA, Suslina ZA. Principles of diagnostics and treatment of patients in the acute period of stroke, Consilium Medicum. 2001;3(5):221-225. Russian language.

6. Gusev El, Skvortsova VI, Stakhovskaya LV. Epidemiology of stroke in Russia, Journal of Neurology and Psychiatry. 2003;8:4-9. Russian language.

7. Kobysheva NV. Management of Specialized Climate Services Economy, Publisher Asterion, Saint-Petersburg; 2008.

8. Hosmer D, Lemeshow S. Applied Logistic Regression, John Wiley and Sons Inc., USA; 1989.

9. Leonov VP. Logistic regression in the medicine and biology, Biometrica [Online], March 10:2013. Available: http://www.biometrica.tomsk.ru/logit 1.htm (accessed March 10, 2013). Russian language.

10. Agresti A. An Introduction to Categorical Data Analysis, John Wiley and Sons Inc., USA; 1996.

11. Varakin UY. Epidemiology of vascular disease of the brain. / / Essays angioneurology. Publishing House Atmosphere; 2005.

12. Schmidt EV, Makinskaya TA. Stroke. Morbidity and mortality. Journal of Neurology and Psychiatry. 1979;4:427-439. Russian language.

13. Bevan H. et al. Stroke in young adults. Stroke. 1990.

14. Kappelli L.J. et al. Prognosis of young adults with ischemic stroke. Stroke. 1994.

15. Miroshnichenko LI. Solar Activity and the Earth, Publisher Nauka, Moscow. 1981.

16. Zabolotnaya NA. Indices of Geomagnetic Activity: Reference Manual, Publisher LKI, Moscow; 2007.

17. Latyshev GD, Boksha VG. To the question of a medical assessment of weather (weather index and the response of patients). Journal of Questions of Balneology. 1965;4:345-351. Russian language.

18. Belenky PM. The influence of weather - and geleofizicheskih factors on the incidence of stroke in Leningrad. Journal of Neurology and Psychiatry.1978;78(9):1329-1333. Russian language.

19. Breus TK, Komarov FI. Medical effects of magnetic storms. Clinical medicine. 2005;3:4-12. Russian language.

20. Breus TK, Conrad AA. The effects of solar activity rhythms. Atlas temporal variations of natural, anthropogenic and social processes. 2003;C.516. Russian language.

21. Bourtsev EM Cerebrovascular accident at a young vozraste. M.: Medicine. 1978;C.198. Russian language.

22. Valiahmetova DA. The effect heliogeophysical factors on the health of patients with cardiovascular diseases. Kazan Medical Journal. 1989;70:88-90. Russian language. 
23. Vasyuk NM. Influence of some meteorological factors on the course and outcome of vascular diseases of the brain (according to Zaporozhye). Ivano-Frankivsk. 1979;22c. Russian language.

24. Golovchenko Y. Meaning meteostressa development of vascular disease. Neurology and psychiatry. Kiev. 1986;5:11-12. Russian language.

25. Gorbulev JL. The influence of meteorological factors on the occurrence and nature of stroke in Baku. Azerbaijan Medical Journal.1986;7:22-24. Russian language.

26. Grigoriev II. Medical and weather forecasting - the most important branch of modern science meteopatologii. Questions Health Resort. 1993;6:42-46. Russian language.

27. Grigoriev II. Weather and health. Moscow. 1996;C.121. Russian language.

28. Grigoriev II. Weather and the human body. Questions Health Resort. 1998;5:53-56. Russian language.

29. Grunskaya LV, Leshchev IA. The influence of the electromagnetic field of the boundary layer of the atmosphere on health and human biorhythms. Proceedings of the II Russian Congress on Chronobiology and chronomedicine with international participation. Journal Bulletin of the Russian University of People's Friendship. 2012;7:81-83. Russian language.

30. Grublyak VT Meteorological characteristics of the incidence of stroke in KamenetzPodolsk. Medical business.1981;2:57-59. Russian language.

31. Gusev El. Etiological factors and risk factors for chronic cerebral vascular insufficiency and ischemic stroke. Appendix to the Journal of Neurology and Psychiatry (Stroke). 2001;1:41-45. Russian language.

32. Desyatov VP, Osipov AI, Suzdal OV. Solar activity and mortality statistics. The sun, electricity, life. - Moscow; 1972. Russian language.

33. Kleimenova NG, Kozyrev O. Magnetic storms and infarction: is the danger of the storm? Geophysical processes and the biosphere. 2008;7(3):5-24. Russian language.

34. Komarov FI, Rapoport SI, Breus TK, Baevsky RM, Gurfinkel YI. Chronobiological aspects of the nature and effects of magnetic storms on the functional state of the people. Sat Chronobiology and chronomedicine. Triad, Moscow; 2000. Russian language.

35. Kolodchenko VP. Elements of the influence of geomagnetic disturbances on humans and animals. Proceedings of the 2nd All-Union Conference on the effects of electromagnetic fields on biological objects, 1969;C.125. Russian language.

36. Lapwings SM. Cosmos and the Biosphere: the influence of magnetic storms on hronostrukturu rhythms of the heart. Bulletin RUDN Series Medicine. 2006;35:35-44. Russian language.

37. Lapwings SM, Breus TK, Illarionov TS. The morphological and functional status of the heart during a magnetic storm. Bulletin of Experimental Biology and Medicine. 2001;132(12):627-630. Russian language.

(C) 2013 Martirosyan and Krupskaya; This is an Open Access article distributed under the terms of the Creative Commons Attribution License (http://creativecommons.org/licenses/by/3.0), which permits unrestricted use, distribution, and reproduction in any medium, provided the original work is properly cited.

Peer-review history:

The peer review history for this paper can be accessed here: http://www.sciencedomain.org/review-history.php?iid=205\&id=12\&aid=1367 